\title{
Cross wedge rolling of a Ti6Al4V (ELI) alloy: the experimental studies and the finite element simulation of the deformation and failure
}

\author{
Metin Çakırcalı • Cenk Kılıçaslan • Mustafa Güden • \\ Engin Kuranlı • Valery Y. Shchukin • \\ Vladimir V. Petronko
}

Received: 24 January 2012 / Accepted: 21 May 2012 /Published online: 6 June 2012

(C) Springer-Verlag London Limited 2012

\begin{abstract}
The cross wedge rolling (CWR) deformation and fracture of a Ti6Al4Al (ELI) alloy were investigated experimentally and numerically using a coupled thermomechanical finite element model analysis. The experimentally determined flow stress and damage model parameters were verified by tension split Hopkinson pressure bar testing of notched samples. The simulation and experimental CWR forces showed well agreements except near the end of the stretching zone. The model analysis showed that the temperature distribution in the work piece was nonuniform during the CWR. When the initial temperature of the work piece was relatively low, the work piece temperature increased, a heating effect of the plastic deformation, while relatively high initial work piece temperatures resulted in cooling the work piece, caused by the work piece contact with the tools. The cracks were shown numerically to initiate in the midsections of the work piece during the guiding action and elongated in a direction normal to the maximum tensile stress triaxiality, resulting in cruciformshaped crack formation, which was well agreed with the previously observed crack shape.
\end{abstract}

Keywords Cross wedge rolling · Ti6Al4V · Simulation · Material model $\cdot$ Failure

M. Çakırcalı • C. Kılıçaslan • M. Güden $(\varangle) \cdot$ E. Kıranlı Dynamic Testing and Modeling Laboratory and Department of Mechanical Engineering, Izmir Institute of Technology, Gulbahce Koyu,

Urla, Izmir, Turkey

e-mail: mustafaguden@iyte.edu.tr

V. Y. Shchukin • V. V. Petronko

Physical Technical Institute of NAS Belarus,

Minsk, Belarus

\section{Introduction}

The cross wedge rolling (CWR) is a plastic forming process, in which the cylindrical work pieces are deformed into axisymmetric stepped parts between two or more wedge tools, moving tangentially relative to work piece. The process is conducted at an elevated temperature to acquire relatively low deformation forces. The CWR has been determined to have potentials for the process automation, higher production rates, lower material cost, higher rate of material utilization and less hazardous material disposal to the environment $[1,2]$. Nevertheless, the CWR has not found widespread applications among the metal forming industry, partly due to the lack of adequate technical knowledge on work piece failure mechanisms and partly due to the complexity of tool design [3]. There are basically three major defect groups in the CWR [4]. Excessive slip between work piece and tools results in improper deformation, misalignment and irregular cross-section of work piece. Surface defects including spiral groove, necking, and overlapping occur at relatively high frictional forces between tool and work piece, large reduction ratios $\left(\delta=\frac{d_{0}}{d}\right.$; where $d_{0}$ is the initial and $d$ is the final diameter of work piece) and sharp forming angles $(\alpha)$, respectively. The internal defects including voids and cracks cannot be detected visually; their detections necessitate the implementation of nondestructive inspection techniques. Two types of internal defects, namely centerline cracks (oriented along the work piece) and annular cracks, were reported to occur [5]. The internal void formation or crack initiation was caused by (1) large tensile stresses along the central portion of work piece, (2) excessive shear stresses in the knifing zone, and (3) low cycle fatigue [3, $6,7]$. The voids initiated during the knifing and guiding action and the cruciform-shaped cracks propagated through the direction of the maximum principal stress [8]. 
Finite element (FE) analyses were previously performed in order to understand the relationships between interfacial slip and frictional coefficient $(\mu)$, forming angles and reduction ratio $[2,7,9]$. The distributions of the strain, stress, strain rate, and temperature of work piece and tool forces were numerically investigated [5, 10-14]. A positive maximum principal stress was found at the center of work piece throughout the rolling process, while the stress at the mid-radius exhibited a cyclic variation, leading to axial annular cracks and wellknown Manessmann effect due to low cycle fatigue [5]. Various material models, including Cowper-Symonds flow stress [7, 15] and bilinear kinematic hardening [5] models, have been implemented in the CWR process modeling. The maximum effective plastic strain [6], the first principal stress [9], the dimensionless crushing parameter [15], and Cockcroft, Cockcroft-Latham, Brozzo, and Oyane models [16] were previously investigated as the failure/fracture criteria. The microstructural variations of work piece during the CWR were analyzed using a thermo-mechanical simulator $[14,17,18]$. The applied coupled thermo-mechanical analyses clearly indicated that the touching surface of work piece was cooled down gradually when it was in contact with the tools, and it was re-heated after losing the contact with the tools [11, $13,14]$. As a result of the heat losses by convection and conduction, the temperatures of the center and surface of work

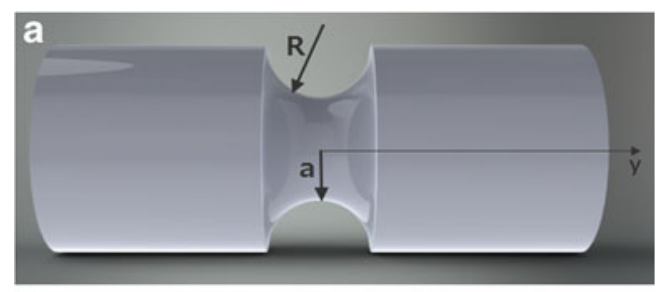

b

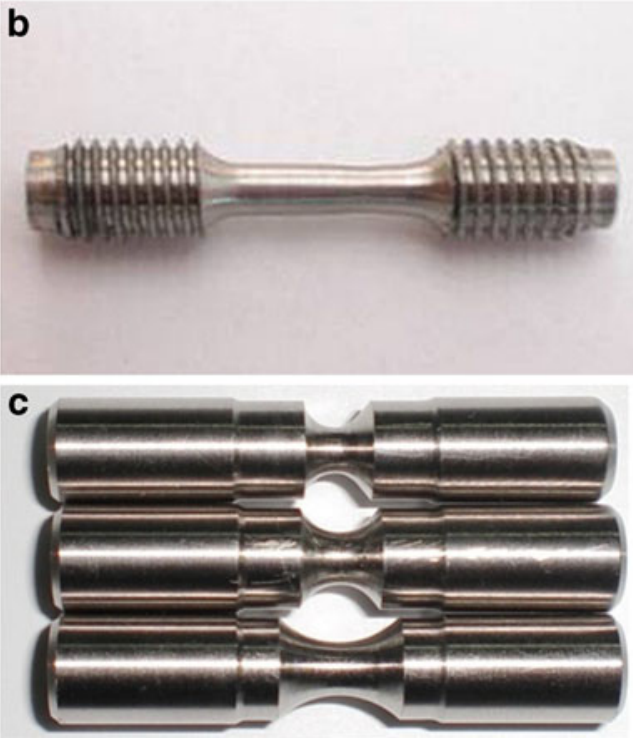

Fig. 1 a The geometrical parameters of notched sample, b TSHPB test sample, and $\mathbf{c}$ quasi-static notched test samples

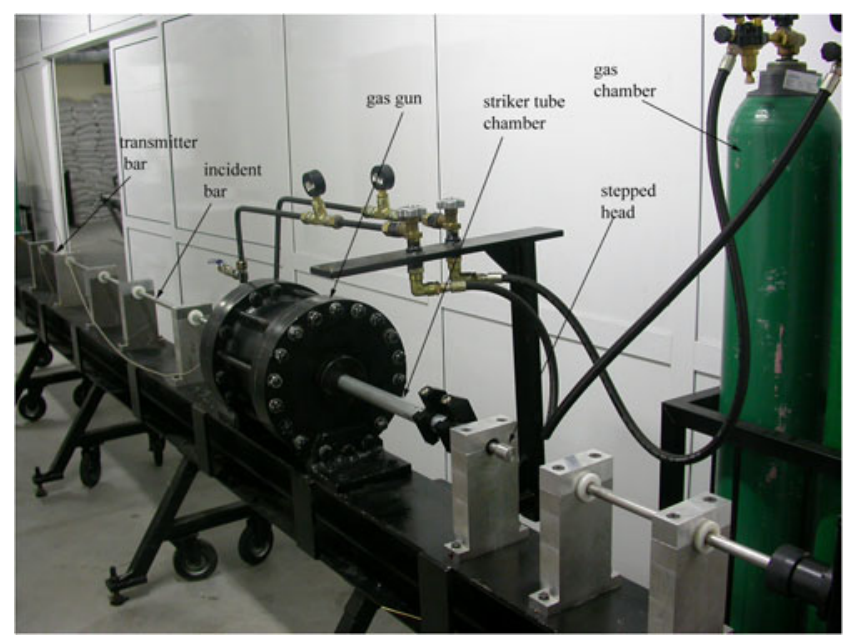

Fig. 2 TSHPB set-up; gas gun assembly and bars

piece either increased or decreased depending on the initial work piece and tool temperatures $[11,13,14]$.

In the present report, a coupled thermo-mechanical FE analysis was conducted in order to monitor the CWR deformation/fracture of a Ti6Al4Al (ELI) alloy which has not been investigated previously. In the first part of the study, tension tests at room and elevated temperatures and at quasi-static and high strain rates were performed in order to determine flow stress and damage model parameters. The validities of flow stress and damage model parameters were then verified by high strain rate testing of notched samples in a tension split Hopkinson pressure bar (TSHPB). The modeling efforts allowed to monitor the variations of the work piece temperature and proved the existence of cruciform-shaped cracks extending at the mid-cross-sections of the work piece.

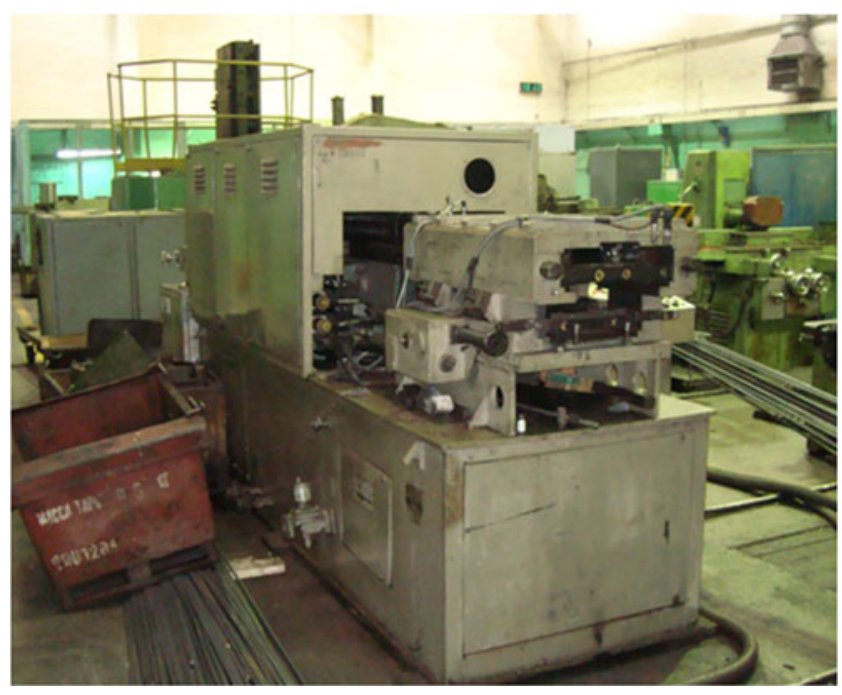

Fig. 3 Experimental CWR machine 
Fig. 4 a The bottom wedge tool and $\mathbf{b}$ tool model a

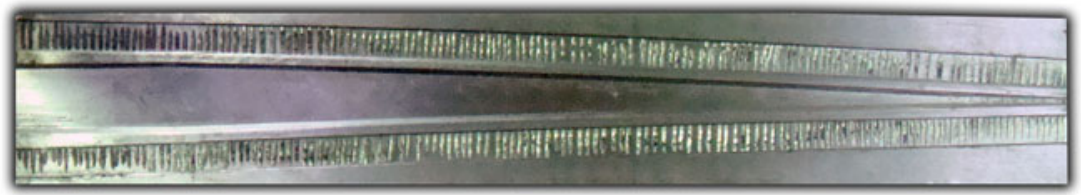

b

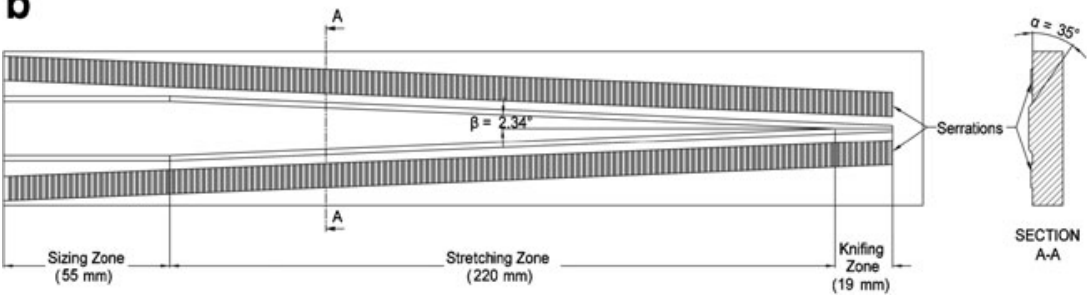

\section{Experiments and modeling}

2.1 Material models and testing methods

The deformation and failure of the studied alloy were modeled using Johnson and Cook (JC) flow stress [4] and damage [19] models given sequentially as

$\sigma=\left[A+B \varepsilon^{n}\right]\left[1+c \ln \left(\frac{\dot{\varepsilon}}{\dot{\varepsilon_{0}}}\right)\right]+\left[1-\left(T^{*}\right)^{\mathrm{m}}\right]$

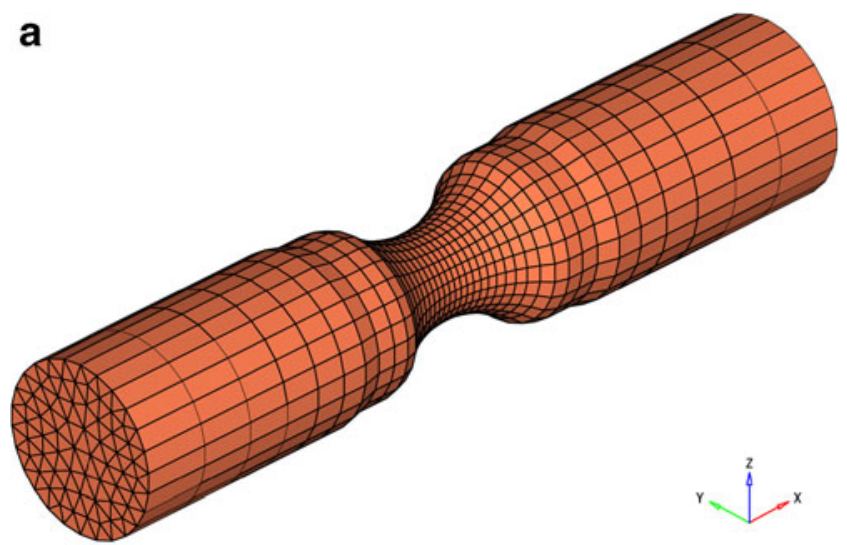

b

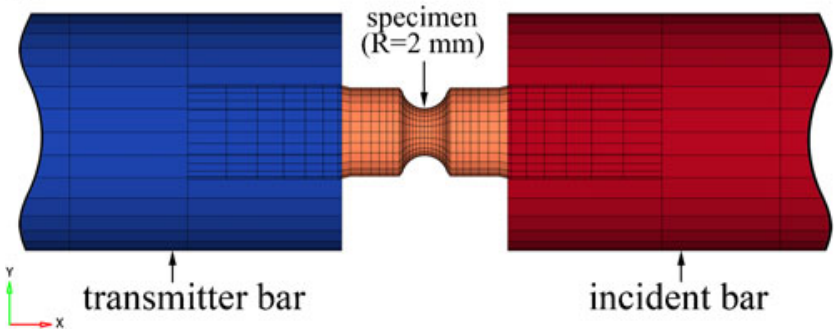

Fig. 5 a The notched sample model and $\mathbf{b}$ assembly of notched sample model in TSHPB, $R=2 \mathrm{~mm}$ and

$\varepsilon^{\mathrm{f}}=\left[D_{1}+D_{2} e^{\left(D_{3} \sigma *\right)}\right]\left[1+D_{4} \ln \left(\frac{\dot{\varepsilon}}{\dot{\varepsilon_{0}}}\right)\right]\left[1+D_{5} T^{*}\right]$

where, $\varepsilon, \dot{\varepsilon}, \dot{\varepsilon_{0}}$, and $\varepsilon^{\mathrm{f}}$ are, respectively, the effective plastic strain, strain rate, reference strain rate, and failure strain; $A$, $B, n, c, m, D_{1}, D_{2}, D_{3}, D_{4}$, and $D_{5}$ are the model parameters. The last term $T^{*}$ is expressed as

$T^{*}=\frac{T-T_{\mathrm{r}}}{T_{\mathrm{m}}-T_{\mathrm{r}}}$

where $T$ is the temperature and $T_{\mathrm{r}}$ and $T_{\mathrm{m}}$ are the reference and melting temperatures, respectively. In Eq. $2, \sigma^{*}$ is the stress triaxiality and for a notched round sample given as [20]

$\sigma^{*}=\frac{\sigma_{\mathrm{h}}}{\sigma}=\frac{1}{3}+\ln \left(1+\frac{a}{2 R}\right)$

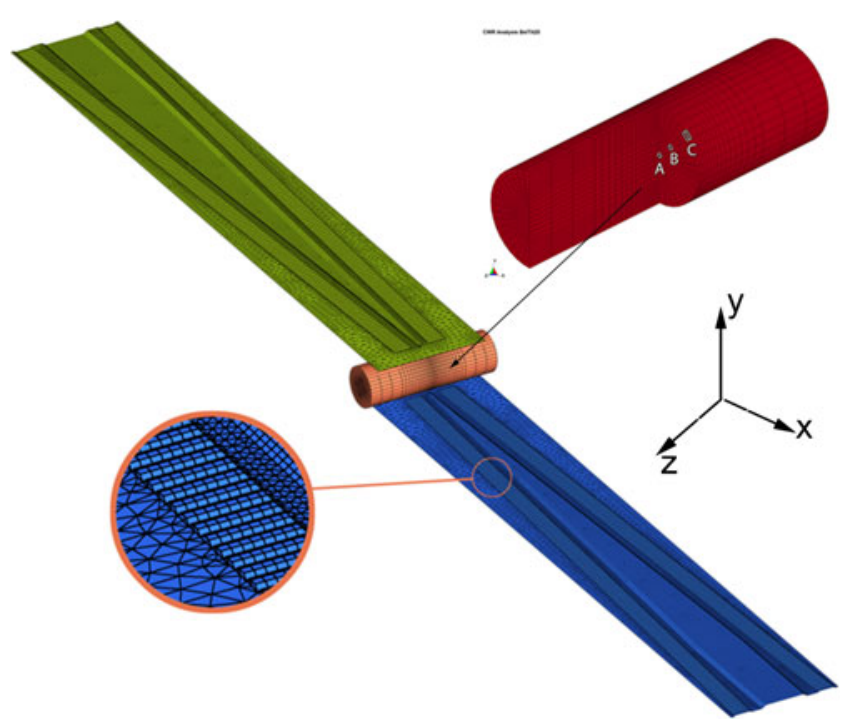

Fig. 6 The CWR model and the analyzed points on the work piece 


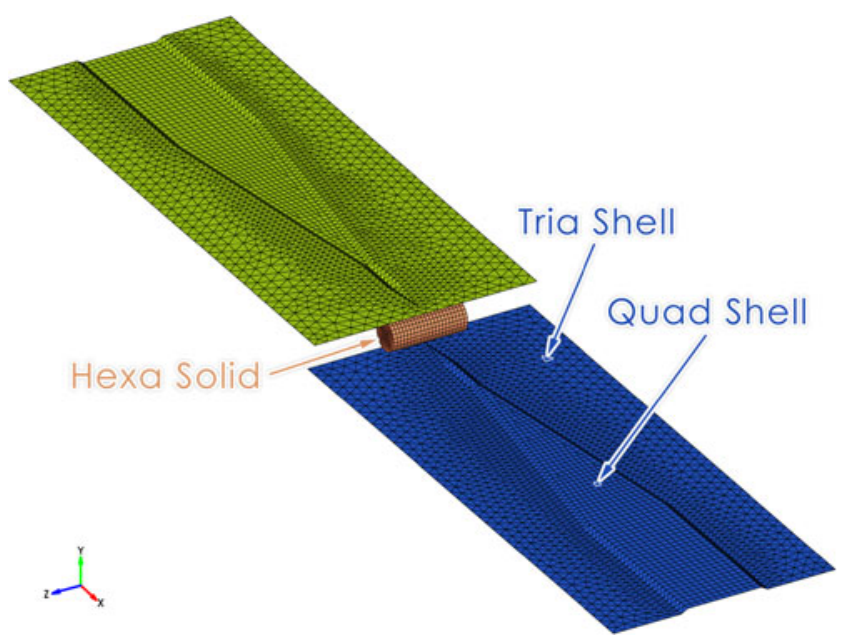

Fig. 7 The CWR model for the failure analysis

where, $\sigma_{\mathrm{h}}$ and $\sigma$ are the mean and equivalent stresses, respectively; $a$ and $R$ are the radius of the smallest cross-section and the radius of curvature at the neck, respectively (Fig. 1a).

Tensile test samples were machined from an annealed biomedical grade, 19-mm diameter Ti6Al4V bar supplied by Titanium Industries. The bar composition reported by the supplier complied with ASTM F136-02a [21] standard and contained relatively low interstitial element concentrations.

The gage length $(10 \mathrm{~mm})$ and diameter $(4 \mathrm{~mm})$ of the quasi-static and high strain rate tensile test samples were the same, except that the high strain rate test samples had treats at both ends, which were used to screw the test samples to the TSHPB incident and transmitter bar ends (Fig. 1b). Quasistatic tests at room temperature $\left(25^{\circ} \mathrm{C}\right)$ were conducted using a displacement-controlled SHIMADZU AG-I test machine at strain rates of $1 \times 10^{-3}, 1 \times 10^{-2}$, and $1 \times 10^{-1} \mathrm{~s}^{-1}$. Hightemperature tensile tests $\left(500,900,1,050\right.$, and $\left.1,100{ }^{\circ} \mathrm{C}\right)$ were performed at $1 \times 10^{-3} \mathrm{~s}^{-1}$ in a split furnace inserted into the universal test machine. The true flow stresses at a constant true strain were determined from the experimental true stress-true strain curves as function strain rate and temperature.

The TSHPB set-up was very similar to the set-up used in reference [22] and made of $316 \mathrm{~L}$ stainless steel bars $(2 \mathrm{~cm}$ in diameter), with a striker tube length of $30 \mathrm{~cm}(2 \mathrm{~cm}$ inner diameter and $2.9 \mathrm{~cm}$ outer diameter), incident bar length of $244 \mathrm{~cm}$, and transmitter bar length of $244 \mathrm{~cm}$. The mechanical and physical properties of the bar material are as follows: elastic modulus $=193 \mathrm{GPa}$, density $=8 \mathrm{~g} \mathrm{~cm}^{-3}$, and yield strength $=\sim 300 \mathrm{MPa}$. The loading of the samples in
TSHPB testing was captured using a Photron Fast-Cam high speed camera at 20,000 fps. In a typical TSHPB test, a gas gun fires a striker tube to the steeped end of the incident bar (Fig. 2). This creates a tension wave on the incident bar which moves to the sample-bar interface where it is partly reflected as compressive wave to the incident bar and partly transmitted as tension wave to the transmitter bar. The incident, reflected and transmitted waves are measured by means of strain gages mounted on the incident and transmitter bars. The working principle and formulations used to calculate strain, stress and strain rate in TSHPB are given elsewhere [23, 24]. The strain rate, strain, and stress in the sample are calculated using the following equations based on one-dimensional wave propagation in long bars

$$
\dot{\varepsilon}(t)=\frac{-2 C_{\mathrm{b}}}{L_{\mathrm{s}}} \varepsilon_{\mathrm{r}}(t)
$$

$\varepsilon(t)=\frac{-2 C_{\mathrm{b}}}{L_{\mathrm{s}}} \int_{\mathrm{o}}^{t} \varepsilon_{\mathrm{r}}(t) \mathrm{d} t$

$\sigma(t)=\frac{E_{\mathrm{b}} A_{\mathrm{b}}}{A_{\mathrm{s}}} \varepsilon_{\mathrm{r}}(t)$

where $C_{\mathrm{b}}$ is the elastic wave velocity of the bar, $L_{\mathrm{s}}$ is the sample gage length, and $A_{\mathrm{s}}$ and $A_{\mathrm{b}}$ are the sample and bar cross-sectional areas, respectively. $\varepsilon_{\mathrm{r}}$ and $\varepsilon_{\mathrm{t}}$ are the reflected and transmitted strains, respectively.

The notched round tensile test samples (see Fig. 1c), with three different stress triaxiality parameters $(R=6,3$, and $2 \mathrm{~mm}$; $a=2 \mathrm{~mm}$; and $\sigma^{*}=0.486,0.621$, and 0.738$)$ and unnotched round tensile test samples $\left(a=2 \mathrm{~mm}, \sigma^{*}=0.33\right.$, same as the quasi-static tensile test sample size) were used to determine damage model parameters. These samples were tested quasistatically at strain rates of $1 \times 10^{-3}, 1 \times 10^{-2}$, and $1 \times 10^{-1} \mathrm{~s}^{-1}$. At least three tests were performed at each strain rate. The axial displacements of the samples were recorded by means of a video extensometer. The sample deformation and facture were captured simultaneously during a test using the high speed camera at $50 \mathrm{fps}$. The variations of the sample minimum diameter and radius of curvature were then measured from the video camera records. For each sample tested, the effective plastic fracture strain was calculated as

$$
\varepsilon^{f}=\ln \frac{A_{0}}{A_{\mathrm{f}}}
$$

Table 1 The JC flow stress material model parameters

\begin{tabular}{lrrllllll}
\hline Model & $A(\mathrm{MPa})$ & $B(\mathrm{MPa})$ & $c$ & $n$ & $m$ & $\varepsilon_{0}\left(\mathrm{~s}^{-1}\right)$ & $T_{\mathrm{r}}\left({ }^{\circ} \mathrm{C}\right)$ & $T_{\mathrm{m}}\left({ }^{\circ} \mathrm{C}\right)$ \\
\hline JC-1 & 928 & 1,062 & 0.0167 & 0.62 & 0.75 & $1 \times 10^{-3}$ & 25 & 1,663 \\
$\mathrm{JC}-2$ & 30 & 50 & 0.0167 & 0.62 & 0.42 & $1 \times 10^{-3}$ & 800 & 1,663 \\
\hline
\end{tabular}


where, $A_{0}$ and $A_{\mathrm{f}}$ are the initial and final (fracture) sample cross-sectional areas, respectively. The failure strains were determined from the notched sample tensile tests as function of strain rate and stress triaxiality parameter.
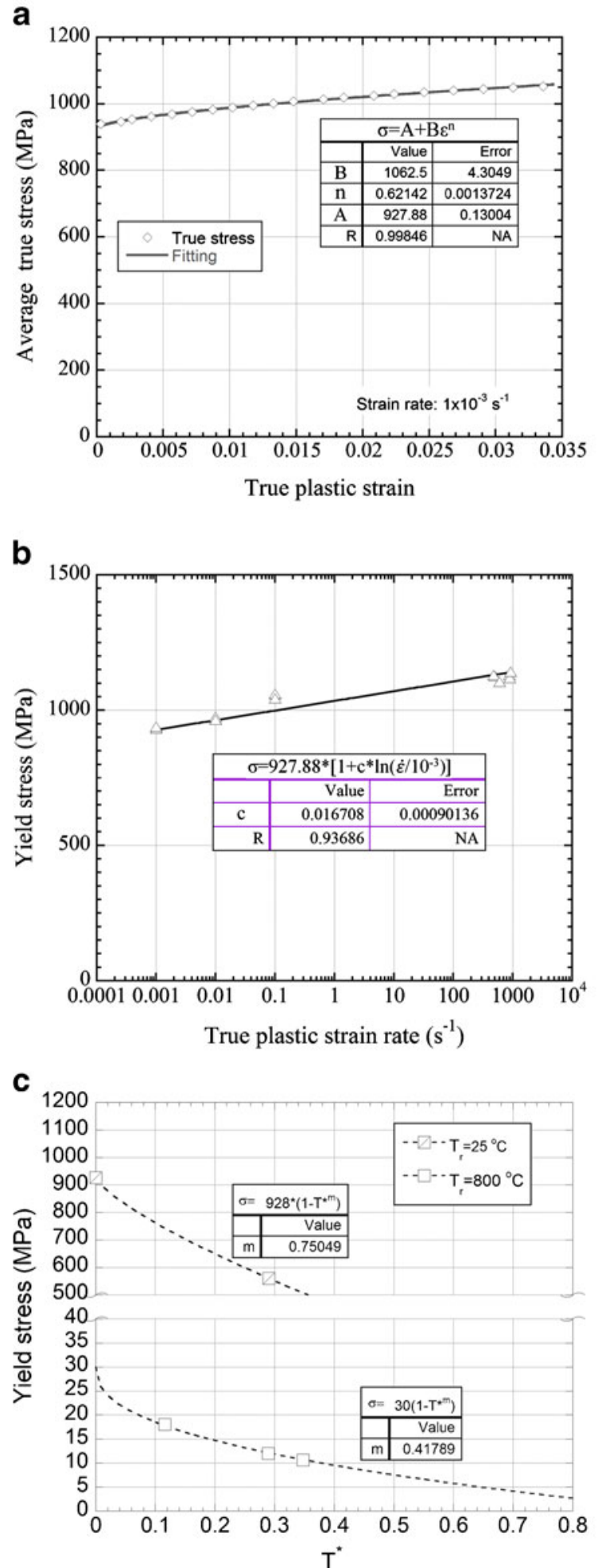

The microscopic analyses of untested and tested samples were performed using a Philips XL30-SFEG scanning electron microscope with an energy dispersive X-ray (EDX) analyzer. The polished cross-sections of the samples were

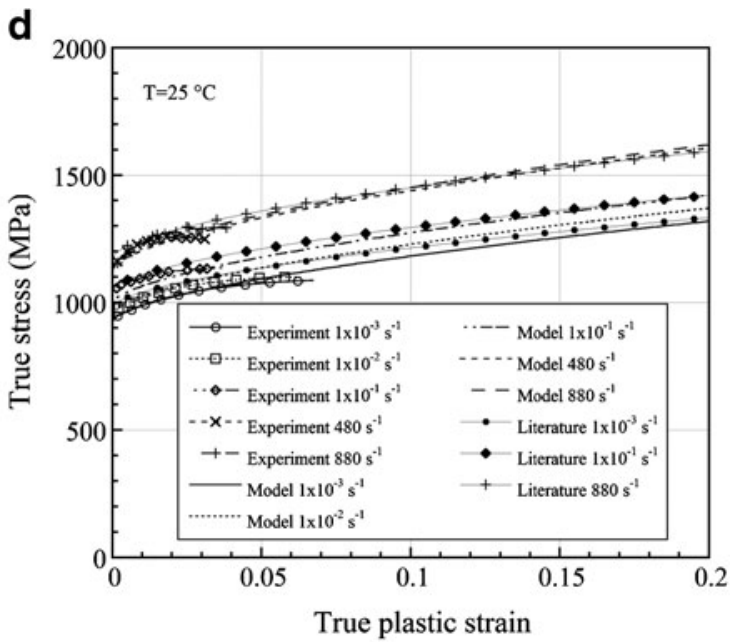

e

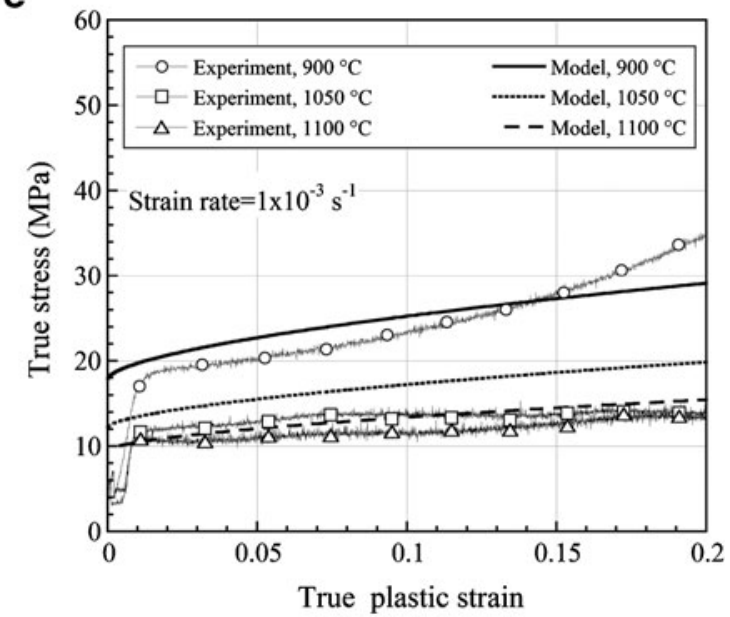

Fig. 8 a Average true stress vs. true plastic strain, b yield stress vs. strain rate, c yield stress vs. $T^{*}$, $\mathbf{d}$ experimental and model true stress-true plastic strain curves of JC-1 model, and e experimental and model true stress-true plastic strain curves of JC-2 model 
Table 2 The JC damage model parameters of Ti6A14V

\begin{tabular}{llllllll}
\hline$D_{1}$ & $D_{2}$ & $D_{3}$ & $D_{4}$ & $D_{5}$ & $\dot{\varepsilon_{0}}\left(\mathrm{~s}^{-1}\right)$ & $T_{\mathrm{r}}\left({ }^{\circ} \mathrm{C}\right)$ & $T_{\mathrm{m}}\left({ }^{\circ} \mathrm{C}\right)$ \\
\hline 0.29 & 8.63 & -8.40 & -0.021 & 4.22 & $1 \times 10^{-3}$ & 25 & 1,663
\end{tabular}

etched with Kroll's reagent $\left(3 \mathrm{~cm}^{3}\right.$ of $\mathrm{HF}$ and $6 \mathrm{~cm}^{3}$ of $\mathrm{HNO}_{3}$ in $100 \mathrm{ml}$ of $\mathrm{H}_{2} \mathrm{O}$ ).

\subsection{The CWR experiments}

The experiments were performed using a flat wedge CWR machine at the Physical Technical Institute of NAS of Belarus (Fig. 3). The work piece was heated to the prescribed rolling temperatures inside an induction furnace. The picture of a flat wedge type tool is shown in Fig. 4a, with the following geometrical parameters: $\alpha=35^{\circ}$, stretching angle $(\beta)=2.34^{\circ}, \delta=1.16$, the knifing zone length $=19 \mathrm{~mm}$, the stretching zone length $=220 \mathrm{~mm}$ and the sizing zone length $=55 \mathrm{~mm}$ (Fig. $4 \mathrm{~b}$ ). A relatively small reduction ratio was preferred in the experiments in order not to damage the tools. In a typical experiment, the bottom wedge tool was stationary, while the upper wedge tool moved laterally with a rolling speed of $0.235 \mathrm{~m} \mathrm{~s}^{-1}$ corresponding to a total CWR time of $1.25 \mathrm{~s}$. The experimental work piece diameter and length were 19 and $60 \mathrm{~mm}$, respectively. The experiments were performed at 25,500 , and $750{ }^{\circ} \mathrm{C}$ initial work piece temperatures. The heating of the work piece to the rolling temperature took between 5 and $7 \mathrm{~min}$. A pressure gage on the hydraulic cylinder measured the tangential forces of the work piece as function of time.

2.3 Modeling cross wedge rolling and TSHPB notch sample tests

The numerical calculations were performed using the LSDYNA V971 solver. Notched test samples were modeled

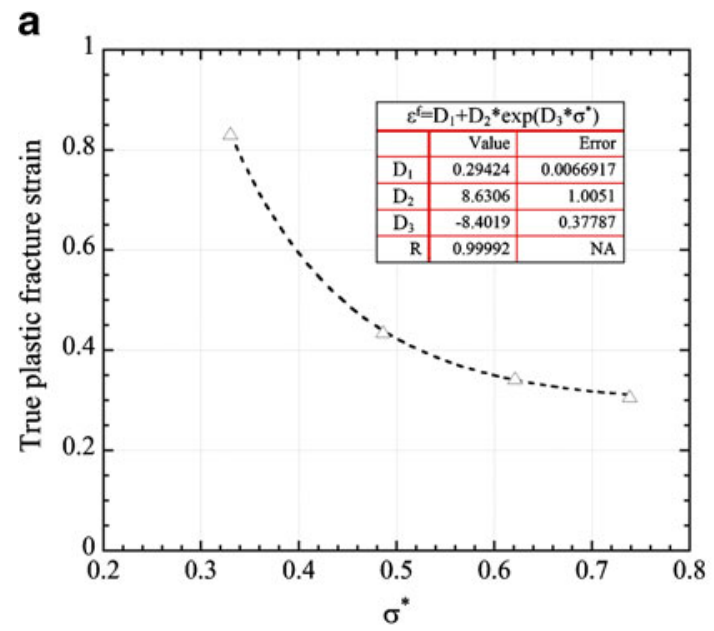

C
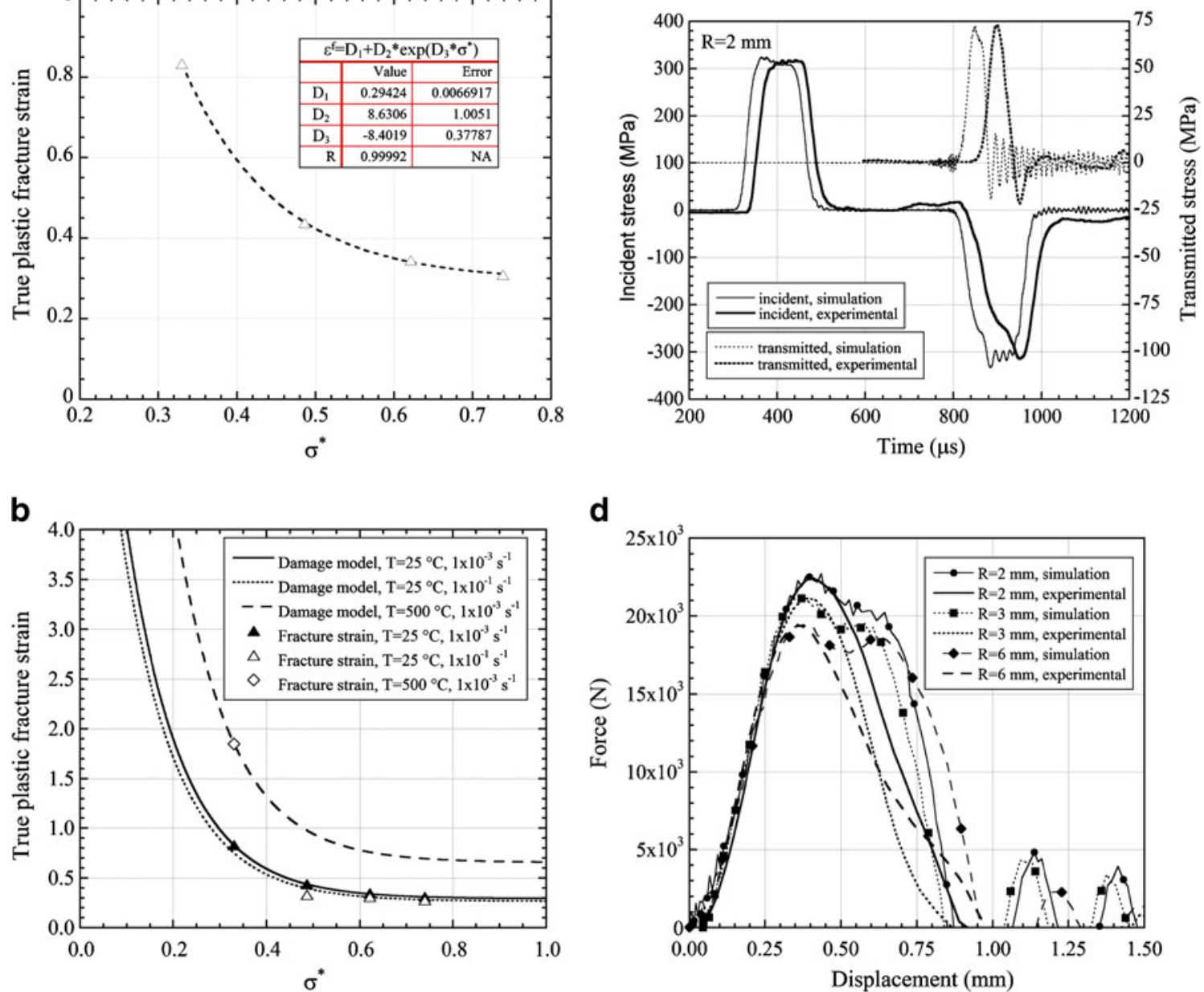

d

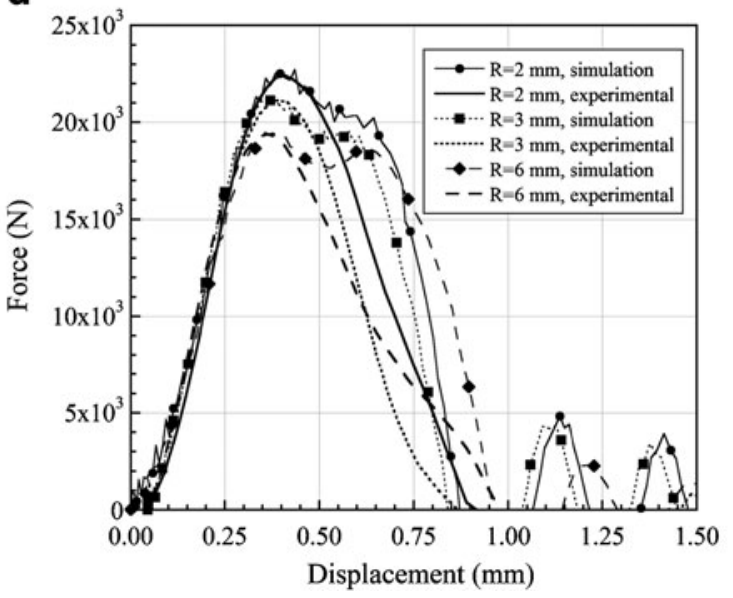

Fig. 9 a True plastic fracture satin vs. stress triaxiality, b experimental and damage model true plastic fracture strain vs. stress triaxiality, $\mathbf{c}$ simulation and experimental TSHPB incident and transmitted stresses

$(R=2 \mathrm{~mm})$ of a notch sample, and $\mathbf{d}$ simulation and experimental forcedisplacement curves of notched samples tested in TSHPB 
using $1 \mathrm{~mm}$ size six-node pentahedral elements (Fig. 5a), except the notched sections were meshed using relatively smaller element size $(0.35 \mathrm{~mm})$ to increase the accuracy of the FE calculations. The TSHPB bars were modeled using the same element type; but, with a coarser size $(10 \mathrm{~mm})$. The TSHPB test model shown in Fig. 5b) comprised 218,938 solid elements.

A combined implicit/explicit solver was used in the numerical simulations. The implicit solver was implemented for the thermal and the explicit solver for the mechanical steps of thermo-mechanical coupling analysis. The tools were meshed using triangular and quad (tool-work piece contact areas) shell elements with Belytschko-Tsay shell element formulation (Fig. 6). The contact regions of the tool including the wedges, serrations and work piece deformation zones were modeled using finer meshes $(1 \mathrm{~mm})$ to avoid element penetrations (Fig. 6). The work piece was modeled using 13,284 solid elements of single-point integration. A bell-curve style biasing along the $z$-axis was applied; the $x y$ cross-section was meshed using butterfly type elements, and the elements around the centroid were smoothed. The serrations on the tool were to align the work piece throughout the CWR process. The tools were modeled using 39,886 shell elements and constrained in all three axes for the rotations
Fig. 10 a Effective strain distributions of the notched samples before and after the fracture in the TSHPB test simulations and $\mathbf{b}$ the pictures of the simulation and experimental deformation shapes of $6 \mathrm{~mm}$ notch sample before and after fracture

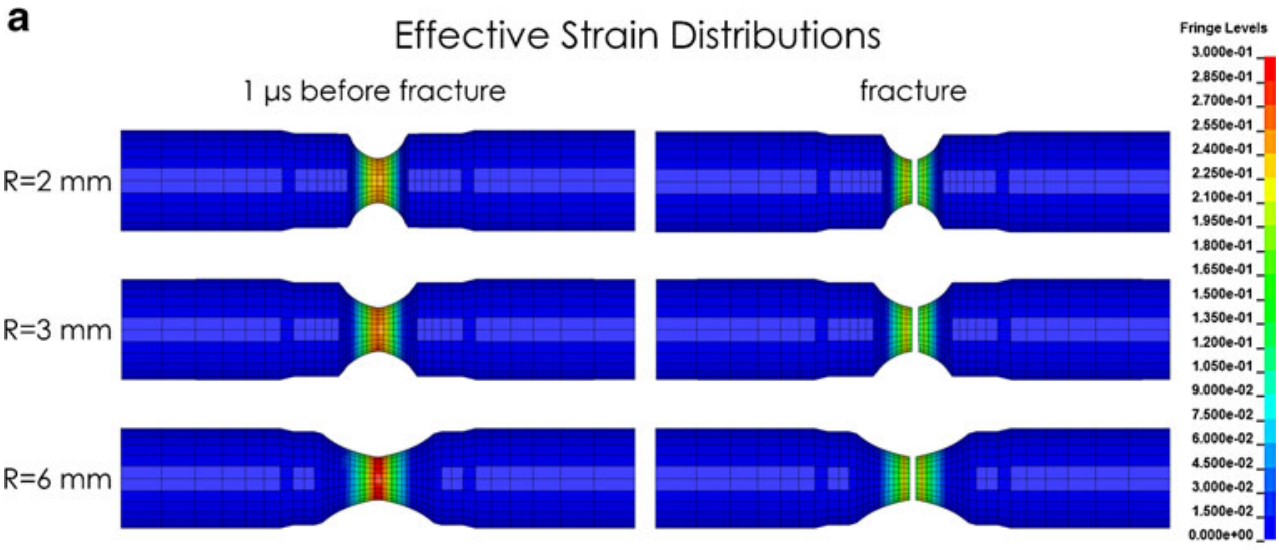

b
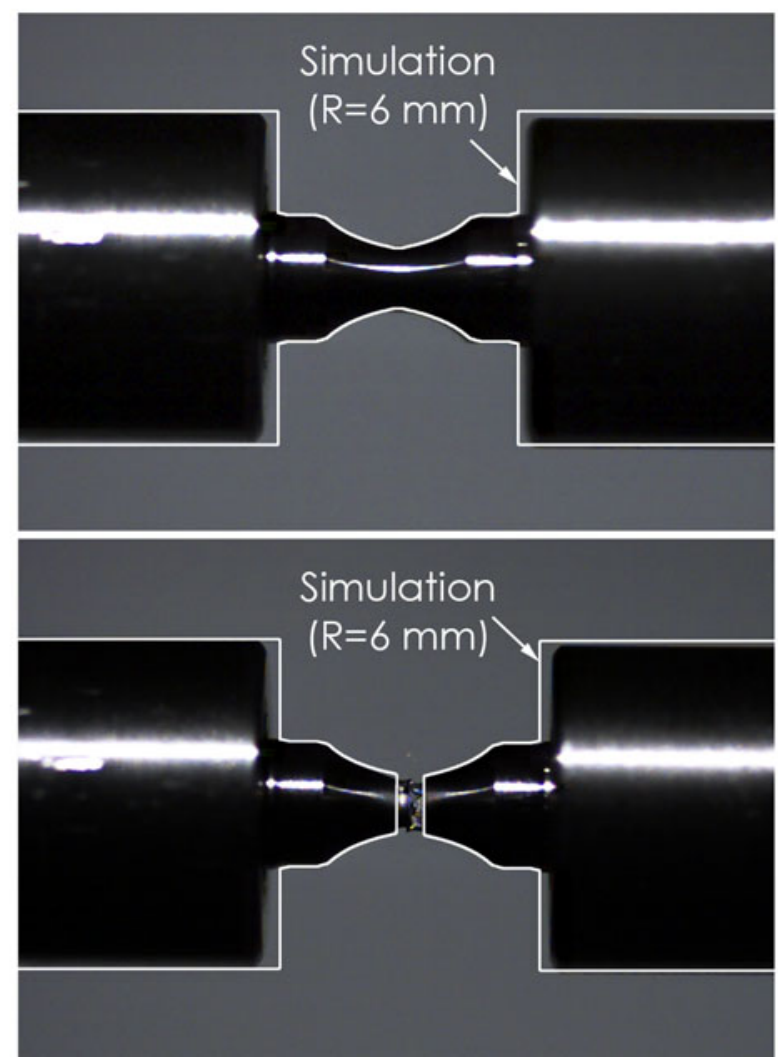
and only in the $y$-and $z$-axis for the translations. The contact between tools and work piece was defined by the surface-tosurface contact algorithm in the LS-DYNA. The tools were assumed rigid and defined by MAT_RIGID material model. In the thermal analysis, the work piece and tools were modeled using MAT_THERMAL_ISOTROPIC material models. The initial temperature of tools was $25^{\circ} \mathrm{C}$, same as the experiments. The heat capacity and thermal conductivity of the work piece were taken as $460 \mathrm{Jkg}^{-1} \mathrm{~K}^{-1}$ and $0.49 \mathrm{~kW} \mathrm{~m}^{-2} \mathrm{~K}^{-1}$, respectively. The heat transfer between work piece and environment was modeled by thermal convection and between work piece and tools by thermal contact conductance. The thermal contact conductance was taken as $10 \mathrm{~kW} \mathrm{~m}^{-2} \mathrm{~K}^{-1}$ [12]. The environment temperature
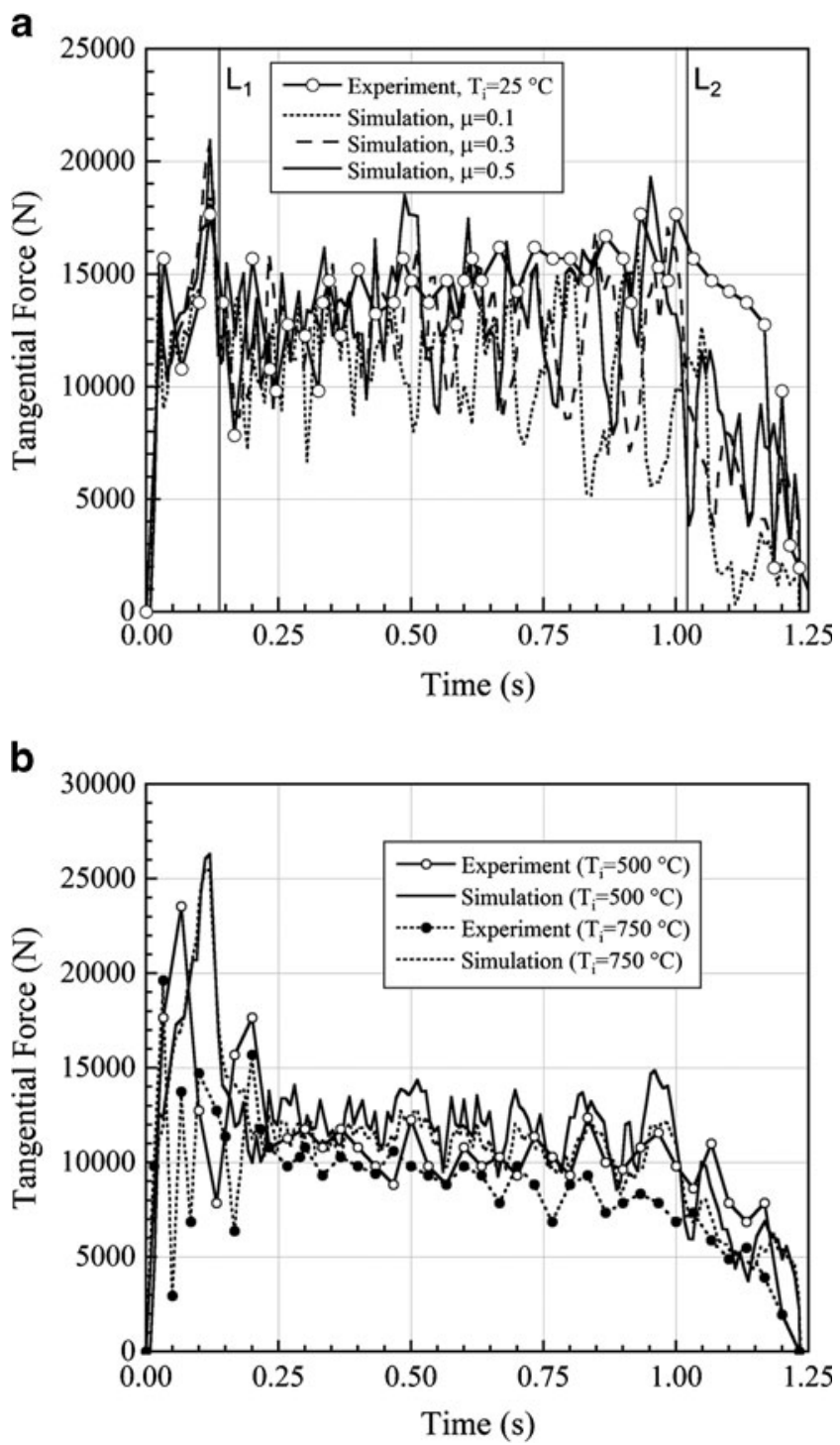

Fig. 11 The variations of experimental and simulation tangential forces of the work piece for a $25{ }^{\circ} \mathrm{C}$ initial work piece temperature and various friction coefficients and for b 500 and $750{ }^{\circ} \mathrm{C}$ initial work piece temperatures was assumed to be constant, $25{ }^{\circ} \mathrm{C}$, and the heat transfer coefficient for convection was taken as $25 \mathrm{Wm}^{-2} \mathrm{~K}^{-1}[13]$. The friction coefficient between work piece and tool surfaces was defined in contact keyword of the LS-DYNA as

$\mu=\mathrm{FD}+(\mathrm{FS}-\mathrm{FD}) \mathrm{e}^{-\mathrm{DC}\left|v_{\text {rel }}\right|}$

where FS and FD are sequentially the static and dynamic friction coefficients, DC is the exponential decay coefficient and $v_{\text {rel }}$ is the relative velocity of the surfaces in contact. The values of FS and FD were set to $0.1,0.3$, and 0.5 for the tests performed at $25{ }^{\circ} \mathrm{C}$ initial work piece temperature and to 0.5 for the tests performed at 500 and $750{ }^{\circ} \mathrm{C}$ initial work piece temperatures. The value of $\mathrm{DC}$ was set to 0.1 . The results of FE model were investigated for the center $(A)$, middle $(B)$, and surface $(C)$ of the middle cross-section of the work piece in the $z$-axis (Fig. 6).

\subsection{Monitoring failure}

The failure of the work piece was simulated using the following tool geometrical parameters: $\alpha=30^{\circ}, \beta=8^{\circ}$, and $\delta=1.21$. The tool model for failure analysis accommodated a guiding zone as seen in Fig. 7. The lengths of the knifing, guiding, stretching and sizing zones were sequentially 35 , 35,215 , and $135 \mathrm{~mm}$, corresponding to a total CWR time of $4 \mathrm{~s}$ at a tool speed of $0.107 \mathrm{~ms}^{-1}$. The diameter and length of the model work piece were 24 and $60 \mathrm{~mm}$, respectively. The tools were meshed using triangle and quadrilateral shell elements and the work piece using $0.4 \times 0.4 \times 0.8 \mathrm{~mm}$ size eight-node hexahedron solid elements. Total 105,952 and 129,600 elements were used to model tools and work piece, respectively. A relatively high reduction ratio and a larger work piece diameter were selected in the model in order to fail the work piece numerically.

\section{Results and discussion}

\subsection{Material model of Ti6Al4VELI alloy}

Two JC flow stress models, JC- 1 model between 25 and $800{ }^{\circ} \mathrm{C}$ and JC-2 model $800-1,100{ }^{\circ} \mathrm{C}$, are determined. The flow stress model parameters of both models are tabulated in Table 1. JC-2 model is used to simulate the work piece deformation above $800{ }^{\circ} \mathrm{C}$. The flow stress model parameters determination consists of curve fittings of Eq. 1 with the experimental flow stresses. Initially, the plastic true stressstrain curves at the reference strain rate of $1 \times 10^{-3} \mathrm{~s}^{-1}$ are fitted with the equation in the first bracket of Eq. $1\left(A+B \varepsilon^{n}\right)$ to determine $A, B$, and $n$ (Fig. 8a). The yield stresses determined at different strain rates are then fitted with the strain rate term, the second bracket of Eq. 1, to determine the value 

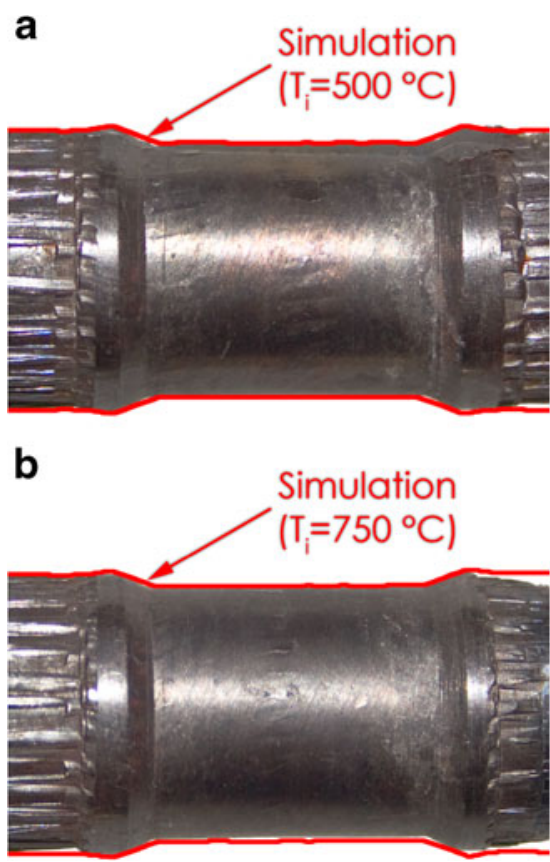

Fig. 12 The pictures of the work piece after CWR: a 500 and b $750{ }^{\circ} \mathrm{C}$ initial work piece temperatures and the simulation deformation shapes (lines)

of $c$ (Fig. 8b).The value of $m$ is determined for the reference temperatures of 25 and $800{ }^{\circ} \mathrm{C}$ by fitting the last term of Eq. 1 with the experimentally determined yield stresses at the reference strain rate (Fig. $8 \mathrm{c}$ ). Figure $8 \mathrm{~d}$ shows the predicted flow stress-strain curves at different strain rates using JC-1 model and Fig. 8e the stress-strain curves between 900 and $1,100{ }^{\circ} \mathrm{C}$ at a strain rate of $1 \times 10^{-3} \mathrm{~s}^{-1}$ using JC-2 model. It is noted in Fig. 8d that model and experimental true stresstrue plastic strain curves show well agreements at the strain levels corresponding to ultimate tensile stresses. In the same figure, the true stress-strain curves of a similar alloy containing slightly higher oxygen content $(0.174 \%)$ than the tested alloy $(0.15 \%)$ are shown for comparison. The comparison curves are drawn using the JC model parameters $(A=$ $1,080 \mathrm{MPa}, B=1,007 \mathrm{MPa}, n=0.5975, c=0.01304, \dot{\varepsilon}_{0}=1 \mathrm{~s}^{-1}$, and $m=0.7701$ ) given in reference [25]. Both models result in similar stress-strain curves at different strain rates until about plastic strains near fracture (not shown in Fig. 8d), despite differences between impurity contents.

The determined JC damage model parameters are tabulated in Table 2. The damage parameters of $D_{1}, D_{2}$, and $D_{3}$ in Eq. 2 are obtained by fitting the experimental true plastic fracture strains at the reference strain rate with the equation in the first bracket of Eq. 2 (Fig. 9a). The parameter $D_{4}$ is determined by fitting the experimentally determined true plastic fracture strains of 2 and $3 \mathrm{~mm}$ notch size samples (at $1 \times 10^{-3} \mathrm{~s}^{-1}, 1 \times 10^{-2} \mathrm{~s}^{-1}$, and $1 \times 10^{-1} \mathrm{~s}^{-1}$ ) with the equation in the second bracket of Eq. 2. The value of $D_{5}$ parameter is determined by fitting the true plastic fracture strains of unnotch samples determined at the reference strain rate with the last brackets of Eq. 2. The variations of model true plastic fracture strains with stress triaxiality at $25\left(1 \times 10^{-3} \mathrm{~s}^{-1}\right.$ and $\left.1 \times 10^{-1} \mathrm{~s}^{-1}\right)$ and $500^{\circ} \mathrm{C}\left(1 \times 10^{-3} \mathrm{~s}^{-1}\right)$ are shown in Fig. $9 \mathrm{~b}$, together with corresponding experimental true plastic fracture strains. As is seen in the same figure, the model and experimental fracture strains are well agreed at increasing temperatures and strain rates. The details of flow stress and damage model parameters determination are given elsewhere [26].

\section{a}

Temperature Distribution $\left({ }^{\circ} \mathrm{C}\right)$
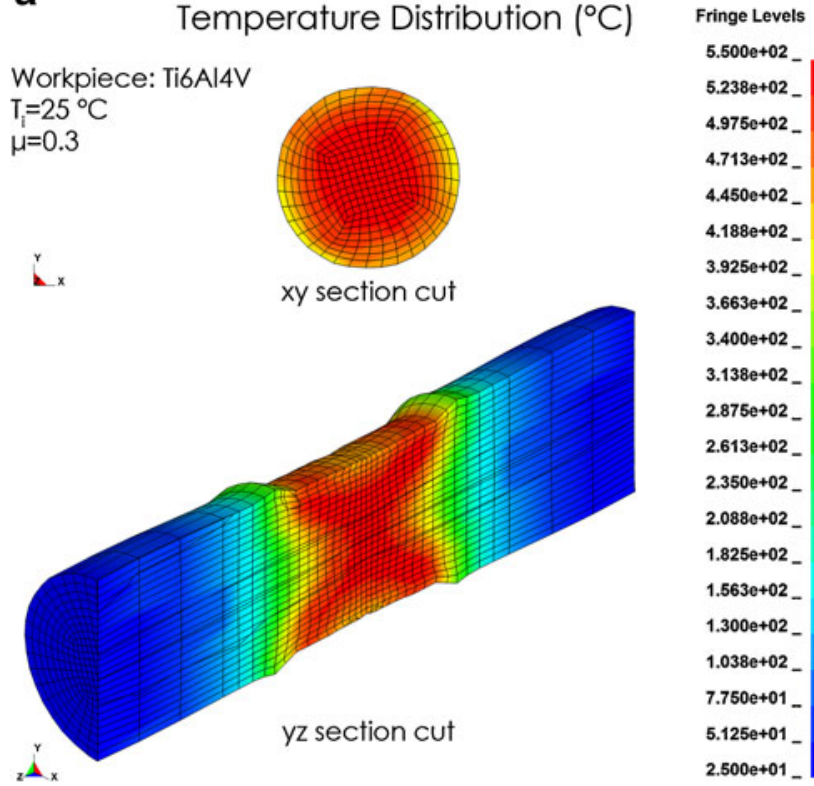

b

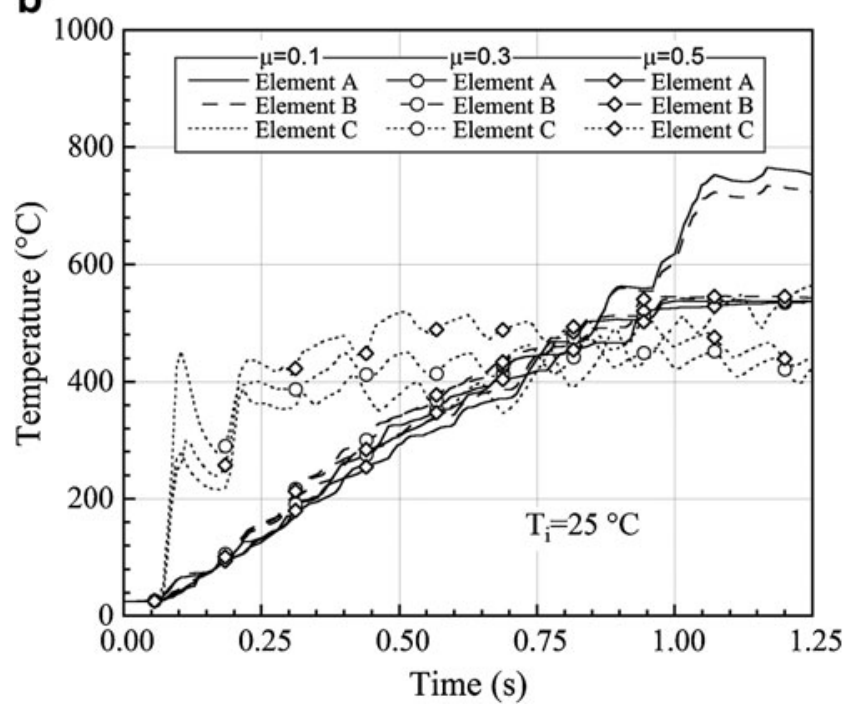

Fig. 13 a The final temperature distributions of Ti6Al4V work piece in the $x y$ and $y z$ cross-sections at the middle and $\mathbf{b}$ the temperature variations of the work piece at $A, B$, and $C$ with the rolling time for the initial work piece temperature of $25^{\circ} \mathrm{C}$ 
Fig. 14 a The final temperature distributions of the work piece (the initial temperatures of 500 and $750{ }^{\circ} \mathrm{C}$ ) in the $x y$ and $y z$ cross-sections at the middle and b the temperature variations of the work piece at $A, B$, and $C$ with rolling time for the initial work piece temperatures of 500 and $750{ }^{\circ} \mathrm{C}(\mu=0.5)$

\section{a}

\section{Workpiece: Ti6Al4V Temperature Distribution $\left({ }^{\circ} \mathrm{C}\right)$} $\mu=0.5$
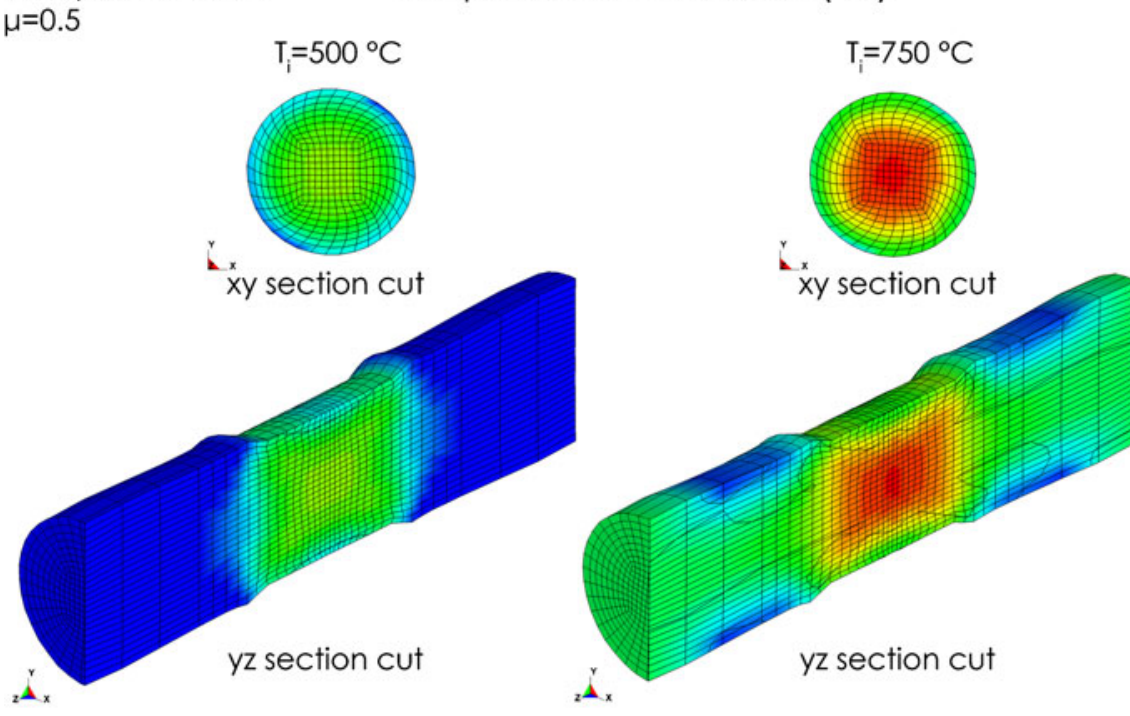

Fringe Levels

$1.0500+03$ $1.023 \mathrm{e}+03$ $9.9500+02$ $9.675 \mathrm{e}+02$ $9.400 \mathrm{e}+02$ $9.125 \mathrm{e}+02$ $8.850 \mathrm{e}+02$ $8.575 \mathrm{e}+02$ 8.300e+02 $8.025 \mathrm{e}+02$ $7.750 \mathrm{e}+02$ $7.475 \mathrm{e}+02$ $7.200 \mathrm{e}+02$ $6.925 \mathrm{e}+02$ $6.650 \mathrm{e}+02$ $6.375 \mathrm{e}+02$ 6.100e+02 $5.825 \mathrm{e}+02$ $5.550 \mathrm{e}+02$ $5.275 \mathrm{e}+02$ $5.000 \mathrm{e}+02$

b

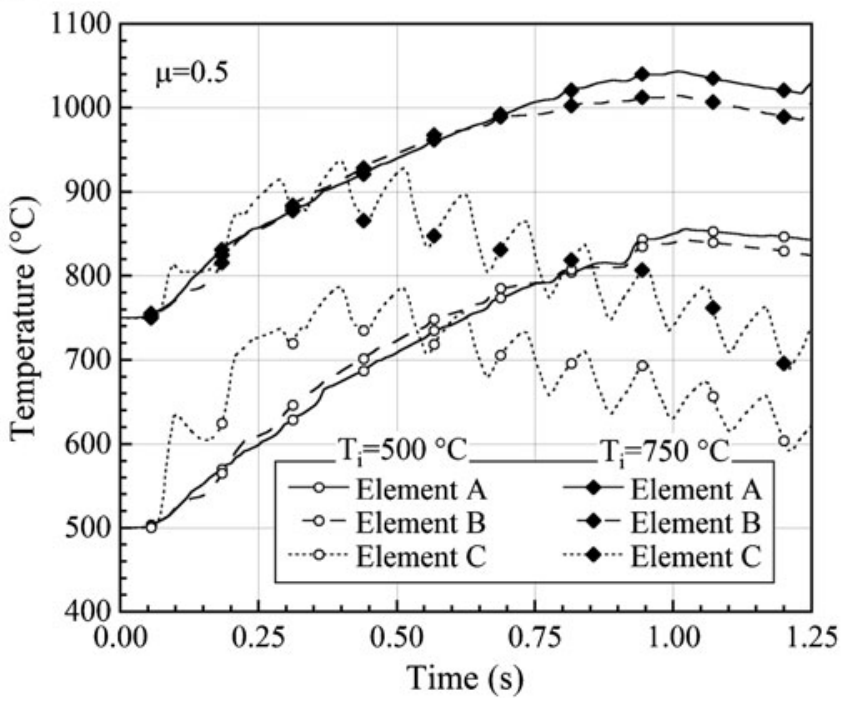

Ti6Al4V $-\mathrm{T}=500^{\circ} \mathrm{C}$

$\mathrm{t}=0.15 \mathrm{~s}$
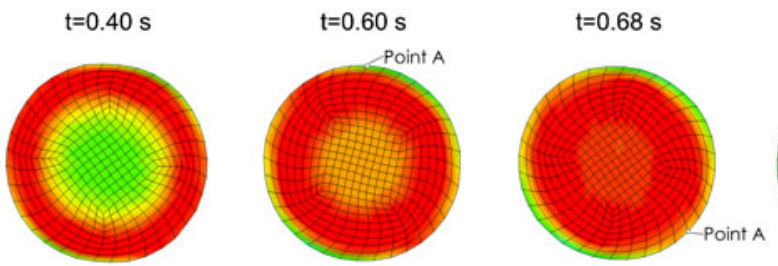

$\mathrm{t}=1.00 \mathrm{~s}$

$t=1.25 \mathrm{~s}$
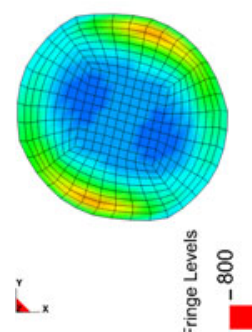

Temperature Distribution $\left({ }^{\circ} \mathrm{C}\right)$

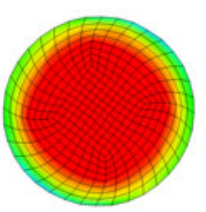

L. $x$

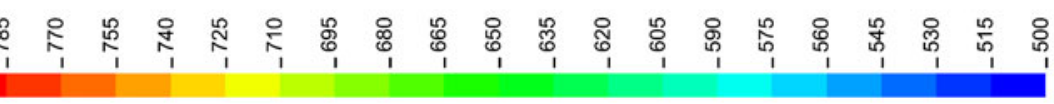

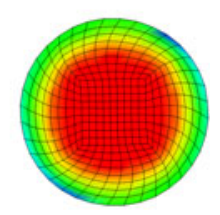

Fig. 15 The temperature distributions of the work piece in the $x y$ cross-section at varying rolling times 

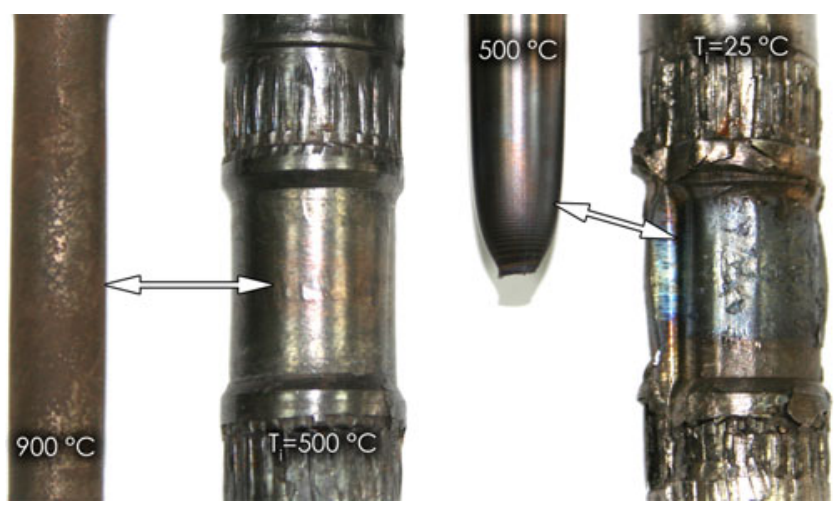

Fig. 16 The final temperature comparisons of the rolled and tensile tested Ti6Al4V samples by surface color

\subsection{Material model verification}

The simulation and experimental TSHBP incident, reflected and transmitted stresses of a $2-\mathrm{mm}$ notch size sample at a striker velocity of $15.3 \mathrm{~ms}^{-1}$ are shown in Fig. 9c. In the numerical simulations, the incident and transmitted waves are measured at a distance of $1.2 \mathrm{~m}$ from the sample-bar interface, the same as the experiments. The experimental stresses in Fig. 9c are however shifted in the time scale with respect to numerical stresses for easy comparison. The fracture initiation in TSHPB is reflected as a sharp drop in the transmitted wave following the initial rise (Fig. 9c). The experimental and numerical stresses are found to be very similar to each other in shape and magnitude. Similar trends were also found in SHPB testing and modeling of 3 and $6 \mathrm{~mm}$ notch size samples (not shown). Figure 9d shows the experimental and numerical force-displacement curves of the notched samples tested in TSHPB. As the notch size increases, the corresponding fracture or maximum force decreases. The simulation and experimental forcedisplacement curves also show well correlations, except the experimental force values show sharp reductions at the onset of and following the fracture. In Fig. 10a, the effective strain distributions of the notched samples just before and after fracture are shown. The highest effective strain is detected in $6 \mathrm{~mm}$ notch size sample. As the notch size decreases, the effective fracture strain decreases near the fracture site, which is in agreement with the variation of the fracture strain with stress triaxiality. Figure $10 \mathrm{~b}$ further
Fig. 17 The stress triaxiality distributions $\mathbf{a}$ before and $\mathbf{b}$ after the crack formation at $0.107 \mathrm{~ms}^{-1}$ tool velocity

\section{a}

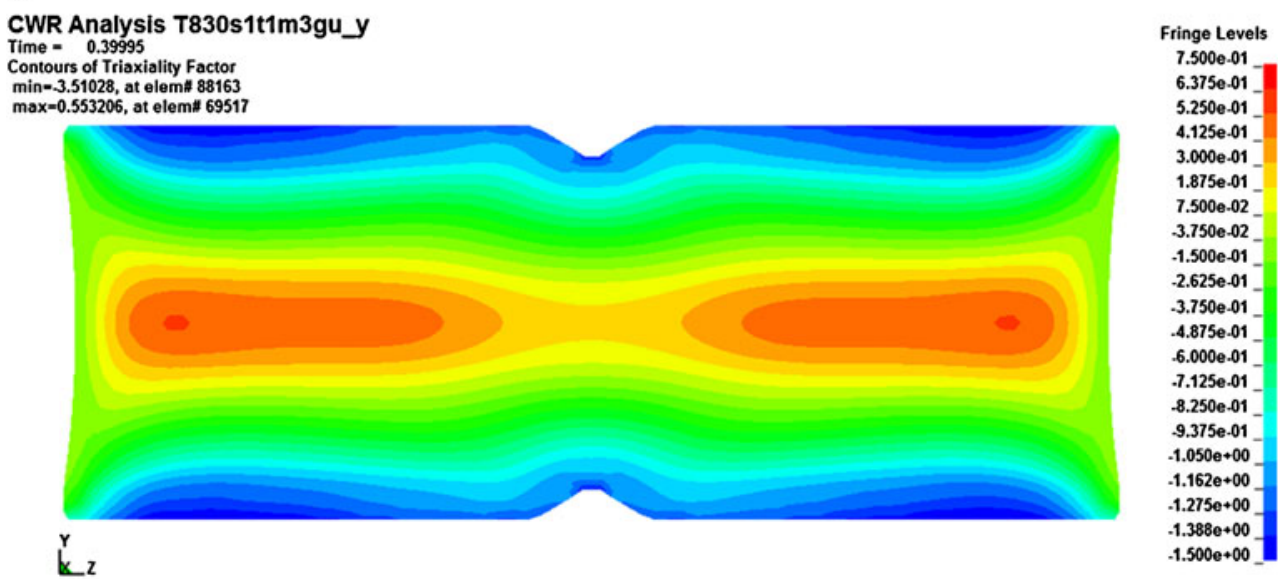

b

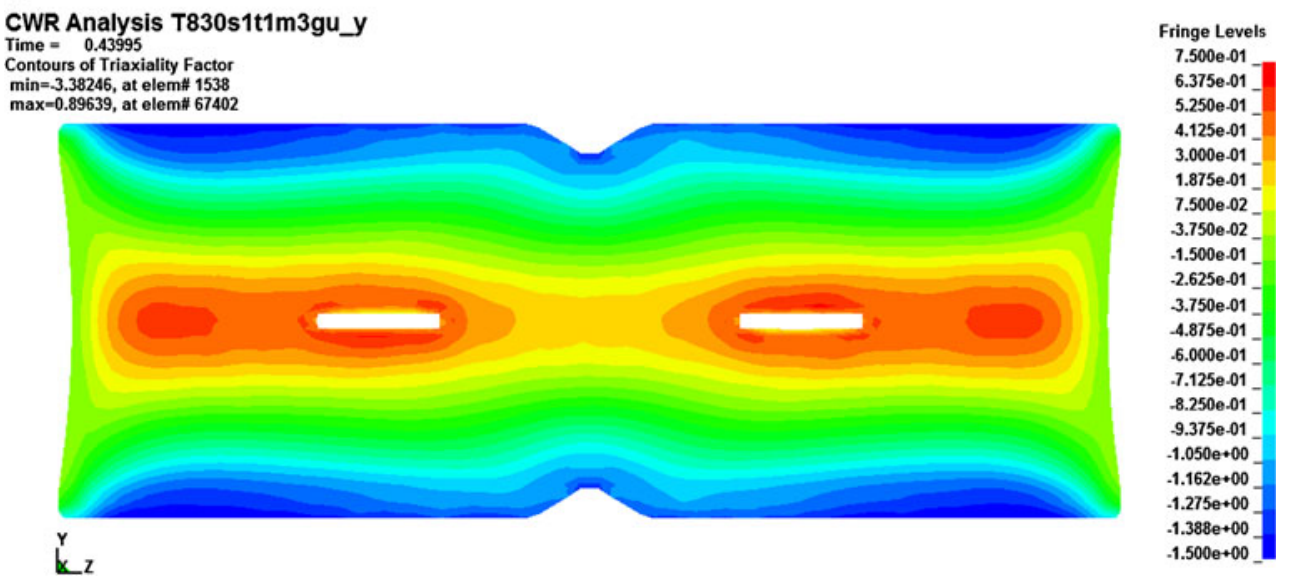


shows the simulation (white line) and experimental deformed pictures of $6 \mathrm{~mm}$ notch size sample before and after fracture. The difference between the simulation and experimental deformed shapes after fracture simply arises from the fact that the elements in the numerical simulation are deleted at the onset of fracture. This naturally results in a shorter final length of the work piece in the simulations. Nevertheless, the simulation and experimental deformation shapes are almost the same just before the fracture, showing the validity of the implemented material flow stress and fracture strain models.

\subsection{CWR process modeling}

The variations of the experimental and simulation tangential forces with time for $25{ }^{\circ} \mathrm{C}$ initial work piece and tool temperature at different friction coefficients are shown in Fig. 11a. The simulation and experimental forces are noted to be very similar initially and through the middle of the stretching zone (from $L_{1}$ to $L_{2}$ in Fig. 11a). From the middle of the stretching zone to the end of deformation, the simulation forces fall below the experimental forces. Increasing friction coefficient tends to increase the simulation forces, particularly at the later stages of the deformation. The difference between simulation and experimental forces is attributed to the increase of the friction coefficient with the deformation in the experiments. Figure $11 \mathrm{~b}$ shows the variations of experimental and simulation tangential forces for 500 and $750{ }^{\circ} \mathrm{C}$ initial work piece temperatures. The simulations were implemented using JC-1 material model with a friction coefficient of 0.5. The simulation and experimental forces agree well and show similar trends. The difference between the simulation and experimental forces is about $10 \%$ on the average. The pictures of the samples experimentally rolled at 500 and $750{ }^{\circ} \mathrm{C}$ are shown in Fig. 12a, b, respectively. The simulation deformed shapes of the work pieces are outlined in the same figures with solid lines. The simulations and experiments end up with the similar final deformation shapes.

The simulation final temperature distributions of the work piece at the middle center ( $x y$ cross-section) and along the $z$-axis ( $y z$ cross-section) are shown in Fig. 13 a for $25^{\circ} \mathrm{C}$ initial work piece temperature. The highest temperature is seen in a region in the middle of the work piece, extending from the shoulder to the center of the work piece. The temperature at the center of the work piece is as high as $550{ }^{\circ} \mathrm{C}$ (Fig. 13a). The variations of the simulation temperatures at the center $(A)$, in the middle $(B)$, and at the surface (C) with time are shown for $25{ }^{\circ} \mathrm{C}$ initial work piece temperature in Fig. 13b. The temperature at the surface is seen to be higher than that in the middle and at the center until about $0.75 \mathrm{~s}$, after which the middle and center temperatures approach the surface temperature. Increasing friction
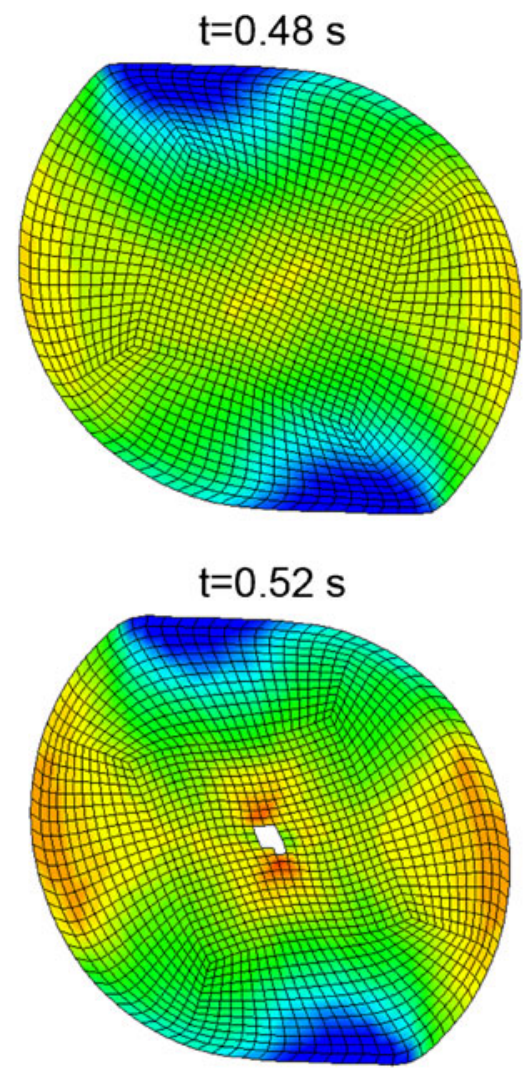

Fringe Levels

$1.000 \mathrm{e}+00$

$8.750 \mathrm{e}-01$

$7.500 \mathrm{e}-01$

$6.250 \mathrm{e}-01$

$5.000 \mathrm{e}-01$

$3.750 \mathrm{e}-01$

$2.500 \mathrm{e}-01$

$1.250 \mathrm{e}-01$

$0.000 \mathrm{e}+00$

$-1.250 \mathrm{e}-01$

$-2.500 \mathrm{e}-01$

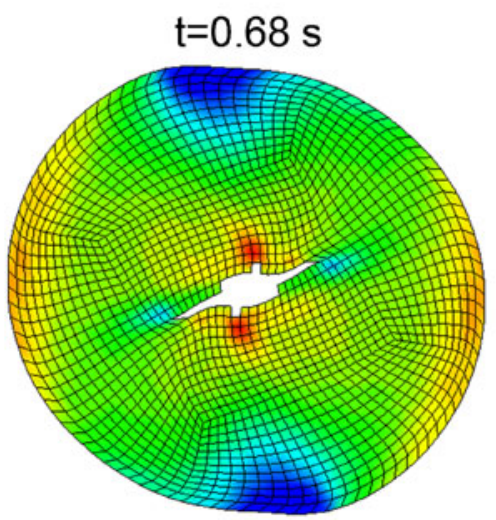

$-3.750 \mathrm{e}-01$

$-5.000 \mathrm{e}-01$

$-6.250 \mathrm{e}-01$

$-7.500 \mathrm{e}-01$

$-8.750 \mathrm{e}-01$

$-1.000 \mathrm{e}+00$

$-1.125 e+00$

$-1.250 \mathrm{e}+00$

$-1.375 e+00$

$-1.500 \mathrm{e}+00$

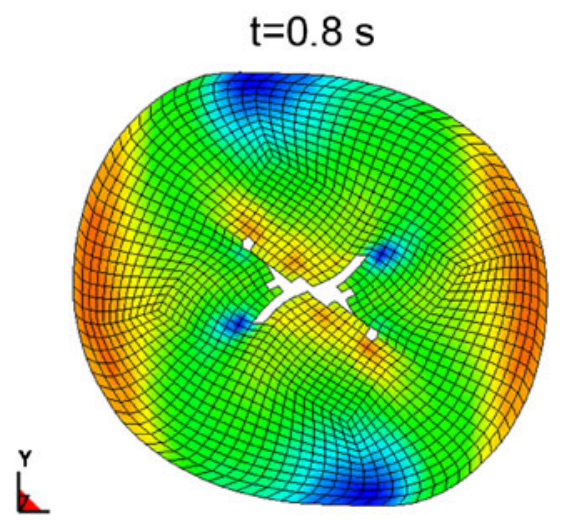

Fig. 18 The stress triaxiality distributions of the work piece, rolled at $0.107 \mathrm{~m} \mathrm{~s}^{-1}$ tool velocity, in the $x y$ cross-section at various deformation times 
coefficient increases the surface temperature, while decreases the middle and center temperatures. The surface temperature varies between 400 and $550{ }^{\circ} \mathrm{C}$ depending on the magnitude of friction coefficient. The fluctuations in the surface temperature profile in Fig. 13b result from the work piece contact and loss of contact with the tools. With increasing the work piece initial temperature to 500 and $700{ }^{\circ} \mathrm{C}$, the highest final temperature shifts from the surface to the center of the work piece as shown in Fig. 14a. The work piece final temperature at the center increases to 900 and $1,050^{\circ} \mathrm{C}$ for the work piece initial temperatures of 500 and $750{ }^{\circ} \mathrm{C}$, respectively. Again, the surface of the work piece initially attains a higher temperature than that of the middle and center, but it quickly cools and the temperature falls below that of middle and center as the deformation progresses (Fig. 14b). In accord with previous applied thermomechanical analysis $[11,13,14]$, the work piece surface is cooled by thermal contact conductance when it is in contact with the tools and it is reheated by the conduction and the heat generated from the plastic deformation when the surface losses the contact with the tools (Fig. 14b). The temperature profiles of the work piece $\left(T_{\mathrm{i}}=500{ }^{\circ} \mathrm{C}\right)$ at different rolling times are shown in Fig. 15. In accord with above, the highest temperature shifts from the surface at $0.4 \mathrm{~s}$ to the center at $0.6 \mathrm{~s}$.

The surface pictures of the work pieces rolled at 25 and $500{ }^{\circ} \mathrm{C}$ initial temperatures are shown in Fig. 16, together with those of the tensile test samples tested at 500 and $900{ }^{\circ} \mathrm{C}$. The surface color of the sample rolled at $25^{\circ} \mathrm{C}$ is near blue, the same as that of the sample tensile tested at $500{ }^{\circ} \mathrm{C}$. Similarly, the surface color of the sample rolled at $500{ }^{\circ} \mathrm{C}$ is very much similar that of the sample tensile tested at $900{ }^{\circ} \mathrm{C}$ (light brown). The similar surface colors of the rolled and high temperature tested samples confirm the attainment of the simulated surface temperatures in the experiments.

\subsection{Failure}

The formation of internal voids in the work piece is simulated using the tool model in Fig. 7. The stress triaxiality distribution before and after crack formation on the $y z$ crosssection is shown in Fig. 17a, b, respectively. The failure occurs at about $0.44 \mathrm{~s}$, in the guiding zone following the knifing zone (finishes at $0.34 \mathrm{~s}$ ) before the work piece enters to the stretching zone (starts at $0.68 \mathrm{~s}$ ). The cracks form at the mid sections, near the shoulder of the work piece, where
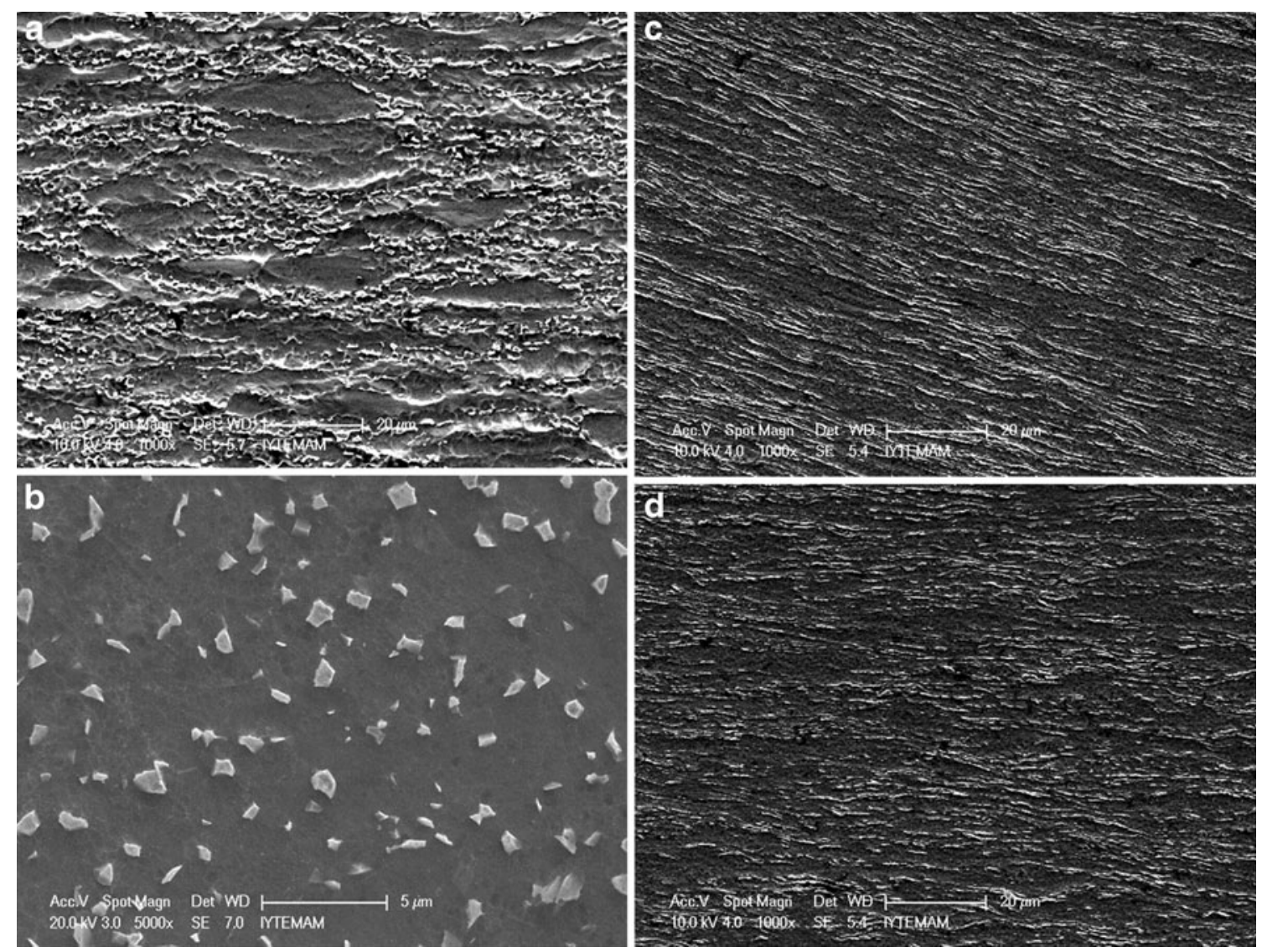

Fig. 19 SEM micrographs showing the microstructure of the work piece a along and $\mathbf{b}$ normal to the extrusion direction before CWR and the microstructure of the work piece $\mathbf{c}$ near the shoulder region and $\mathbf{d}$ in the extension region after CWR (white regions are $\beta$ phase) 

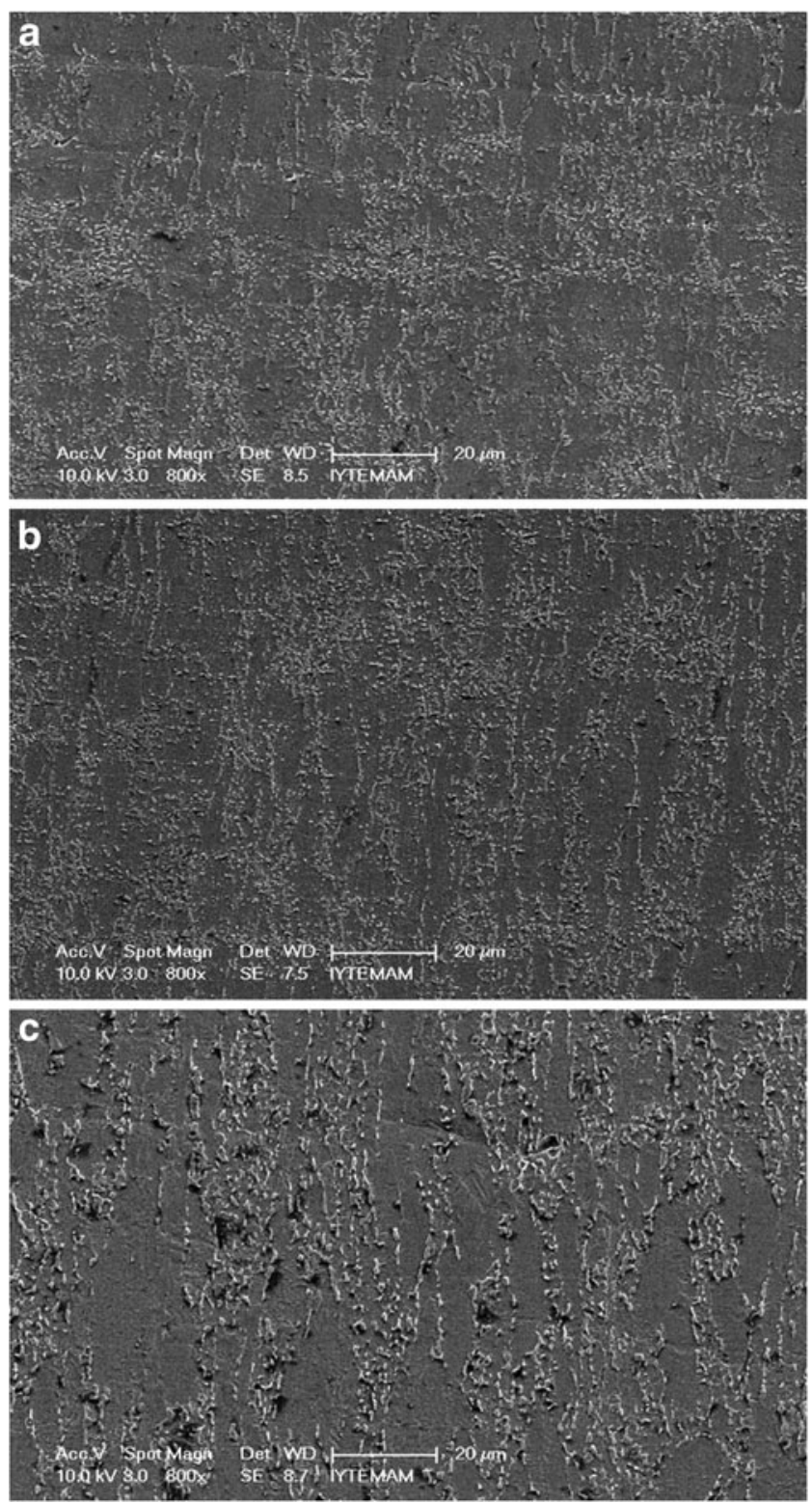

Fig. 20 The microstructure of the work piece in the extension region: a 25 , b 500 , and $\mathbf{d} 750{ }^{\circ} \mathrm{C}$ initial work piece temperatures

the stress triaxiality is the highest (Fig. 17b). Figure 18 further shows the stress triaxiality counters at the mid cross-section at various rolling times. As is seen in the figure, the crack propagates to the mid cross-section at $0.52 \mathrm{~s}$ and elongates in a direction normal to the maximum stress triaxiality at 0.68 and $0.8 \mathrm{~s}$. The above-explained phenomenon of crack formation also quite well agrees with the experimentally observed crack formation in the knifing and guiding zones in cruciform shapes propagating through the direction of the maximum principal stress in CWR [8].

Finally, it should be noted that the implemented failure model cannot capture the failures resulting from compression and shear. Therefore, the failure resulting from excessive shear stresses in the knifing zone and low cycle fatigue in the stretching zone cannot be monitored by the model.

\subsection{Microscopy}

The microstructure of the studied alloy is shown in Fig. 19a and composed of $\alpha$ (hcp) and $\beta$ (bcc) grains. The $\beta$ phase (white), rich in vanadium (determined through EDX analysis) and found around $\alpha$ grain, is slightly elongated through the extrusion direction (Fig. 19a). The size of $\beta$ grains is around $1-2 \mu \mathrm{m}$ (Fig. 19b). The microstructures of the work piece near the shoulder in the extension region after rolling at $25{ }^{\circ} \mathrm{C}$ initial work piece temperature are shown in Fig. 19c, d, respectively. The elongated $\beta$ grains seen in the same figures are normal to rolling direction and confirm the higher deformability of $\beta$ phase. For comparison, the microstructures of the work pieces rolled at 25,500 , and $750{ }^{\circ} \mathrm{C}$ at the mid sections of the work piece are shown in Fig. 20a-c, respectively. The effect of increasing temperature is to increase of the sizes of $\beta$ phase particularly at $750{ }^{\circ} \mathrm{C}$, leading to the increased deformability of the work piece.

\section{Conclusions}

The simulation and experimental CWR forces showed well agreements except near the end of the stretching zone. The difference between simulation and experimental forces at the later stages of the stretching zone was attributed to the increase of the friction coefficient during CWR. Increasing friction coefficient tended to increase the simulation forces, particularly at increasing rolling times. The simulations also revealed that the temperature distribution in the work piece was non-uniform. When the initial temperature of the work piece was relatively low, the work piece temperature increased, a heating effect of the plastic deformation, while higher initial work piece temperatures caused the cooling of the work piece. The failure was shown to occur numerically at the midsections of the work piece in the guiding zone; the cracks elongated in a direction normal to the maximum stress triaxiality due to the high tensile stresses. This resulted in cruciform-shaped crack formation, agreed with the observed experimental crack shape previously.

Acknowledgements The authors would like to thank the Scientific and Technical Council of Turkey (TUBITAK) and NAS of Belarus for the grant \# 107M628.

\section{References}

1. Pater Z (1995) Theoretical method for estimation of mean pressure on contact area between rolling tools and workpiece in cross wedge rolling processes. In: International Conference on the 
Advances in Materials Processing Technologies (AMPT 95), Dublin, Ireland, Aug 1995. Pergamon-Elsevier, Oxford, pp. 233-243

2. Dong Y, Tagavi KA, Lovell MR (2000) Analysis of interfacial slip in cross-wedge rolling: a numerical and phenomenological investigation. J Mater Process Technol 97(1-3):44-53

3. Pater Z (1998) A study of cross wedge rolling process. J Mater Process Technol 80-1:370-375

4. Johnson W, Mamalis AG (1977) A survey of some physical defects arising in metal working processes. Paper presented at the Proc 17th International MTDR Conference, London, UK

5. Dong YM, Tagavi KA, Lovell MR, Deng Z (2000) Analysis of stress in cross wedge rolling with application to failure. Int J Mech Sci 42(7):1233-1253

6. Li Q, Lovell MR (2004) The establishment of a failure criterion in cross wedge rolling. Int J Adv Manuf Technol 24(3-4):180-189. doi:10.1007/s00170-003-1607-0

7. Li Q, Lovell M (2005) On the critical interfacial friction of a tworoll CWR process. J Mater Process Technol 160(2):245-256. doi:10.1016/j.jmatprotec.2004.06.022

8. Li Q, Lovell MR, Slaughter W, Tagavi K (2002) Investigation of the morphology of internal defects in cross wedge rolling. In: 9th International Conference on Metal Forming (METAL FORMING 2002, Birmingham, England, 09-11 Sep 2002. Elsevier, Amsterdam, pp. 248-257

9. Dong YM, Lovell M, Tagavi K (1998) Analysis of interfacial slip in cross-wedge rolling: an experimentally verified finite-element model. J Mater Process Technol 80-1:273-281

10. Fang G, Lei LP, Zeng P (2002) Three-dimensional rigid-plastic finite element simulation for the two-roll cross-wedge rolling process. In: 10th International Manufacturing Conference in China (IMCC 2002), Xiamen, People's Republic of China, 11-13 Oct 2002. Elsevier, Amsterdam, pp. 245-249

11. Li XT, Wang MT, Du FS (2006) The coupling thermal-mechanical and microstructural model for the FEM simulation of cross wedge rolling. J Mater Process Technol 172(2):202-207. doi:10.1016/ j.jmatprotec.2005.10.011

12. Pater $Z$ (2006) Finite element analysis of cross wedge rolling. J Mater Process Technol 173(2):201-208. doi:10.1016/j.jmatprotec. 2005.11.027

13. Qiang YF, Song PB (2006) Analysis on temperature distribution in cross wedge rolling process with finite element method. In: $3 \mathrm{rd}$ International Conference on Advanced Forming and Die Manufacturing Technology, Busan, SOUTH KOREA, 04-06 Sep 2006. Elsevier, Amsterdam, pp. 392-396. doi:10.1016/j.jmatprotec. 2006.11.193

14. Wang MT, Li XT, Du FS, Zheng YZ (2005) A coupled thermalmechanical and microstructural simulation of the cross wedge rolling process and experimental verification. Mater Sci Eng AStruct Mater Prop Microstruct Process 391(1-2):305-312

15. Urankar S, Lovell M, Morrow C, Li Q, Kawada K (2006) Establishment of failure conditions for the cross-wedge rolling of hollow shafts. In: 11th International Conference on Metal Forming 2006, Birmingham, ENGLAND, 11-13 Sep 2006. Elsevier, Amsterdam, pp. 545-549. doi:10.1016/j.jmatprotec. 2006.04.052

16. Lee HW, Lee GA, Yoon DJ, Choi S, Na KH, Hwang MY (2007) Optimization of design parameters using a response surface method in a cold cross-wedge rolling. In: 10th International Conference on Advances in Materials and Processing Technologies (AMPT2007), Daejeon, SOUTH KOREA, 07-11 Oct 2007. Elsevier, Amsterdam, pp. 112-117. doi:10.1016/j.jmatprotec. 2007.11.287

17. Wang MT, Li XT, Du FS, Zheng YZ (2004) Hot deformation of austenite and prediction of microstructure evolution of crosswedge rolling. Mater Sci Eng A-Struct Mater Prop Microstruct Process 379(1-2):133-140. doi:10.1016/j.msea.2004.01.055

18. Xiong Y, Sun SH, Li Y, Zhao J, Lv ZQ, Zhao DL, Zheng YZ, Fu WT (2006) Effect of warm cross-wedge rolling on microstructure and mechanical property of high carbon steel rods. Mater Sci Eng A-Struct Mater Prop Microstruct Process 431(1-2):152-157. doi:10.1016/j.msea.2006.05.148

19. Johnson GR, Cook WH (1985) Fracture chracteristics of 3 metals subjected to various strains, strain rates, temperatures and pressures. Eng Fract Mech 21(1):31-48

20. Bridgman PW (1952) Studies in large plastic flow and fracture. McGraw-Hill, New York

21. ASTM (2003) Standard specification for wrought titanium-6 aluminum-4 vanadium ELI (extra low interstitial) alloy for surgical implant applications. ASTM International, West Conshohocken. doi:10.1520/C0033-03, www.astm.org

22. Chen W, Lu F, Cheng M (2002) Tension and compression tests of two polymers under quasi-static and dynamic loading. Polym Test 21(2):113-121

23. Gray GT (2000) Classic split-Hopkinson pressure bar testing. In: Mechanical testing and evaluation, metals handbook, vol 8. American Society for Metals, Materials Park, pp. 462-476

24. Meyers MA (1994) Dynamic behavior of materials. Wiley, New York

25. Khan AS, Sung Suh Y, Kazmi R (2004) Quasi-static and dynamic loading responses and constitutive modeling of titanium alloys. Int J Plast 20(12):2233-2248

26. Kuranlı E (2009) Determination of material constitutive equation of biomedical grade Ti6A14V alloy for cross edge rolling. Izmir Institute of Technology, Izmir 